\title{
Progreso y evolución de la inserción de la mujer en actividades productivas y empresariales en América del Sur
}

\author{
Beatrice E. Avolio y Giovanna F. Di Laura
}

\section{Resumen}

En 1994, los países de América Latina y el Caribe aprobaron el Programa de Acción Regional para las Mujeres, cuyas directrices se mantienen vigentes por decisión aprobada en la novena Conferencia Regional sobre la Mujer de América Latina y el Caribe (Ciudad de México, 2004), y consolidaron así su compromiso de cumplir los objetivos establecidos en materia de participación equitativa de la mujer en las actividades económicas. La finalidad del presente artículo es analizar el progreso y la evolución de la inserción femenina en el ámbito productivo y empresarial en América del Sur, considerando el panorama laboral femenino, su evolución en la última década y sus diferencias con respecto al panorama laboral masculino. Asimismo, se analizan el uso que hombres y mujeres hacen del tiempo, la participación de la mujer en empleos con un mayor ingreso medio (cargos directivos) y el empoderamiento y la autonomía económica de las mujeres (empresarias).

Palabras clave

Mujeres, adelanto de la mujer, mujeres de negocios, empleo de la mujer, estudio del trabajo, capacidad empresarial, datos estadísticos, América del Sur

Clasificación JEL

J160, J21, J600, J820

Autoras

Beatrice Avolio Alecchi es Directora del Centro de la Mujer, Profesora Principal e Investigadora y Directora General Adjunta de CENTRUM Católica Graduate Business School (PUCP), Perú. bavolio@pucp.pe

Giovanna Francesca Di Laura Mendoza es Profesora e Investigadora de CENTRUM Católica Graduate Business School (PUCP), Perú. gdilauram@pucp.pe 


\section{Introducción}

En la Cuarta Conferencia Mundial sobre la Mujer en Beijing (Naciones Unidas, 1995) se definió una plataforma global de acción para la equidad de género y el empoderamiento de la mujer. En dicha oportunidad se reafirmó el compromiso de desarrollar plenamente el potencial femenino dentro de la sociedad. Uno de los objetivos establecidos en dicha conferencia fue la participación equitativa de las mujeres en las actividades económicas de sus respectivos países. En 1994, los países de América Latina y el Caribe aprobaron el Programa de Acción Regional para las Mujeres de América Latina y el Caribe (1995-2001), cuyas directrices se mantienen vigentes por decisión aprobada en la octava Conferencia Regional sobre la Mujer de América Latina y el Caribe (Lima, 2000) y en la novena Conferencia Regional sobre la Mujer de América Latina y el Caribe (Ciudad de México, 2004) (CEPAL, 2004). A la luz de estos programas y plataformas de acción, se consolida el compromiso de la región para cumplir los objetivos establecidos en materia de participación equitativa de la mujer en las actividades económicas. Así, se han modificado los marcos legales en cada país y creado instituciones orientadas al desarrollo y la promoción de la equidad de género.

En las últimas décadas se registraron importantes cambios en cuanto a la participación de la mujer en el mundo público, en particular su incorporación al mercado laboral, que Kanter (1977) definió como la revolución social silenciosa más importante del siglo XX. Esta incorporación trajo aparejadas profundas transformaciones en diferentes aspectos, incluidos cambios en el mercado laboral, logros educativos, la disminución de la tasa de fecundidad femenina, modificaciones en las relaciones familiares y avances en el acceso a la toma de decisiones (CEPAL, 2004). Sin embargo, aún persisten retos y desafíos a la plena incorporación de la mujer en el mercado laboral. Psacharopoulos y Tzannatos (1989) señalan que, si bien las mujeres constituyen alrededor de la mitad de la población mundial, en gran parte del mundo contribuyen en menor medida que los hombres al valor de la actividad productiva, tanto desde el punto de vista cuantitativo (participación en la fuerza laboral), como cualitativo (logros educativos y habilidades). Esto tiene una serie de repercusiones en el bienestar y el crecimiento económico.

En este contexto, y más de 20 años después de la conferencia de Beijing, es importante establecer el progreso y la evolución de los indicadores relacionados con la participación de la mujer en la actividad económica y productiva, para comprender la situación real de las mujeres y ayudar a la toma de decisiones para la formulación de políticas orientadas a lograr la equidad de género en el mundo del trabajo. El objetivo de este documento es presentar y analizar el progreso y la evolución de la inserción femenina en el ámbito productivo y empresarial en América del Sur. Mediante la comprensión cabal de la participación de la mujer en el mercado de trabajo, se espera brindar información y herramientas para generar iniciativas orientadas a lograr la equidad de género en el ámbito laboral.

El artículo se divide en cinco secciones, incluida esta Introducción. En la segunda se analiza el panorama laboral femenino en América del Sur, su evolución en la última década y sus diferencias con respecto al panorama laboral masculino. Se presentan indicadores referidos a la participación de la mujer en la actividad económica y productiva y se analizan las características del empleo de las mujeres. Asimismo, se incluye el análisis del uso del tiempo que mujeres y hombres en actividades remuneradas y no remuneradas, un aspecto que está vinculado con la división sexual del trabajo y el reforzamiento de los papeles tradicionales asignados en razón del género, que inciden en las posibilidades reales de acceso de la mujer al mercado laboral remunerado y en su permanencia en este.

La importancia de entender las características y la calidad del empleo femenino radica en obtener información que sirva como herramienta para promover el empleo de calidad para las mujeres. 
Es por ello que en la tercera y cuarta secciones se examinan, respectivamente, la participación de la mujer en empleos con un mayor ingreso medio (cargos directivos) y el empoderamiento y la autonomía económica de las mujeres (mujeres empresarias).

Además de la situación de la mujer en altos cargos directivos, en la tercera sección del documento se presentan diversas iniciativas y propuestas en diferentes países para promover una mayor participación de la mujer en este tipo de puestos. Asimismo, se analizan las principales barreras que encuentran las mujeres para acceder a ellos. Se espera que al entender los factores que limitan dicho acceso, se puedan proponer iniciativas que fomenten la participación de la mujer en cargos de alta dirección.

En la cuarta sección se presentan datos sobre la participación y las características de las mujeres empresarias. Es importante resaltar que las mujeres empresarias no solo generan empleo para sí mismas, sino también para otros, con un impacto directo en el desarrollo económico de un país. En la quinta y última sección se formulan algunas reflexiones finales.

\section{La situación laboral y el acceso al empleo}

Las últimas décadas se caracterizan por una serie de cambios en cuanto a la inserción de las mujeres en la actividad económica, tanto a nivel mundial como regional. Según estimaciones de la Organización Internacional del Trabajo (OIT) (2012), la fuerza laboral femenina asciende a 1.300 millones de trabajadoras, alrededor del 39,9\% de la fuerza laboral (3.300 millones) ${ }^{1}$. Entre 1980 y 2008, la tasa de participación femenina en la fuerza laboral se incrementó del 50,2\% al 51,7\%, mientras que la tasa masculina disminuyó del 82\% al 77,7\% (OIT, 2010). Esto refleja una disminución progresiva de la brecha de género en las últimas décadas. La OIT señala que la tasa de participación femenina en 2014 fue del 50,3\%, mientras que la de los hombres fue del 76,7\%, lo que representa una brecha de alrededor de 26 puntos porcentuales (OIT, 2014a). Esta disminución en la tasa de participación con respecto a años anteriores (tanto en el caso de los hombres como de las mujeres) se debe a factores cíclicos, como la recesión y la lenta recuperación de la crisis financiera reciente, y a factores estructurales, como el envejecimiento de la población y el aumento de los años de educación (OIT, 2016).

En la región de América Latina y el Caribe, se observa un incremento significativo en la participación de la mujer en el mercado laboral, que aumentó del 43,5\% en 1992 al 52,6\% en 2012 (OIT, 2012). De acuerdo con la CEPAL (2004), a pesar de estos avances, aún existen diferencias entre hombres y mujeres. En 2002, alrededor de la mitad de las mujeres mayores de 15 años no tenía ingresos propios, mientras que solo cerca del $20 \%$ de los hombres se encontraba en dicha situación. En la actualidad, esa cifra se mantiene para las mujeres a nivel mundial, pues cerca del $50 \%$ de las mujeres no es económicamente activo (OIT, 2014a).

En esta sección se presenta la evolución de los indicadores relacionados con la situación laboral y el acceso al empleo de hombres y mujeres en América del Sur. Para el análisis de la situación laboral, se toman en cuenta indicadores relacionados con el acceso al empleo y su calidad. Por último, se analizan indicadores relacionados con el tiempo dedicado al trabajo remunerado y no remunerado y las diferencias entre hombres y mujeres. Según la CEPAL (2004), los beneficios de la igualdad de género han sido pagados principalmente por las mujeres, que han desarrollado estrategias para optimizar el uso del tiempo debido a la escasa participación de los hombres en las tareas domésticas.

\footnotetext{
1 La expresión "fuerza laboral" se refiere a las personas en edad de trabajar que actualmente trabajan y a las personas que buscan empleo (desempleados) (INSEE, 2016).
} 


\section{Tasa de participación en la fuerza laboral ${ }^{2}$}

La participación de la mujer en el mercado laboral varía de un país a otro, pues refleja diferencias en el desarrollo económico, las normas sociales, los niveles de educación y el acceso a servicios de cuidado infantil (Verick, 2014). La tasa de participación femenina en la fuerza laboral es un eje impulsor del crecimiento, de manera que el análisis de este indicador puede dar indicios sobre el potencial de crecimiento de un país. Pagés y Piras (2010) señalan que la promoción del empleo femenino tiene un impacto directo en el crecimiento económico, no solo de las mujeres sino también de sus familias, al incrementar los ingresos y la seguridad financiera.

Así, la participación de la mujer en la fuerza laboral tiene efectos a nivel macroeconómico, al incrementar el potencial humano disponible y contribuir al crecimiento económico del país, y a nivel microeconómico, ya que genera ingresos directos para su propio bienestar y el de su familia (Pagés y Piras, 2010). De acuerdo con la OIT (2012), la brecha entre hombres y mujeres en la participación en la fuerza laboral ha disminuido a nivel mundial, impulsada principalmente por el incremento del empleo femenino y la disminución de la tasa de participación masculina. No obstante, aún persisten diferencias significativas entre hombres y mujeres.

En el caso de América Latina y el Caribe, la tasa de participación femenina en la fuerza laboral se incrementó 10,1 puntos porcentuales entre 1992 y 2012, mientras que la de los hombres se redujo tres puntos porcentuales en el mismo período (OIT, 2014b). La diferencia en la tasa de participación entre hombres y mujeres se redujo de 39 puntos porcentuales en 1992 a 25,9 puntos porcentuales en 2012 (véase el gráfico 1). No obstante, pese a la reducción de la disparidad entre hombres y mujeres, la tasa de participación femenina aún representa solo el 71,2\% de la participación masculina (OIT, 2013a). Esta tendencia se repite entre 2002 y 2010 en los siguientes países: Argentina, Bolivia (Estado Plurinacional de), Brasil, Chile, Colombia, Paraguay, Perú, Suriname y Uruguay (OIT, 2014c).

\section{Gráfico 1}

América Latina y el Caribe: brecha de género en la tasa de participación en la fuerza laboral, 1992-2012

(En porcentajes)

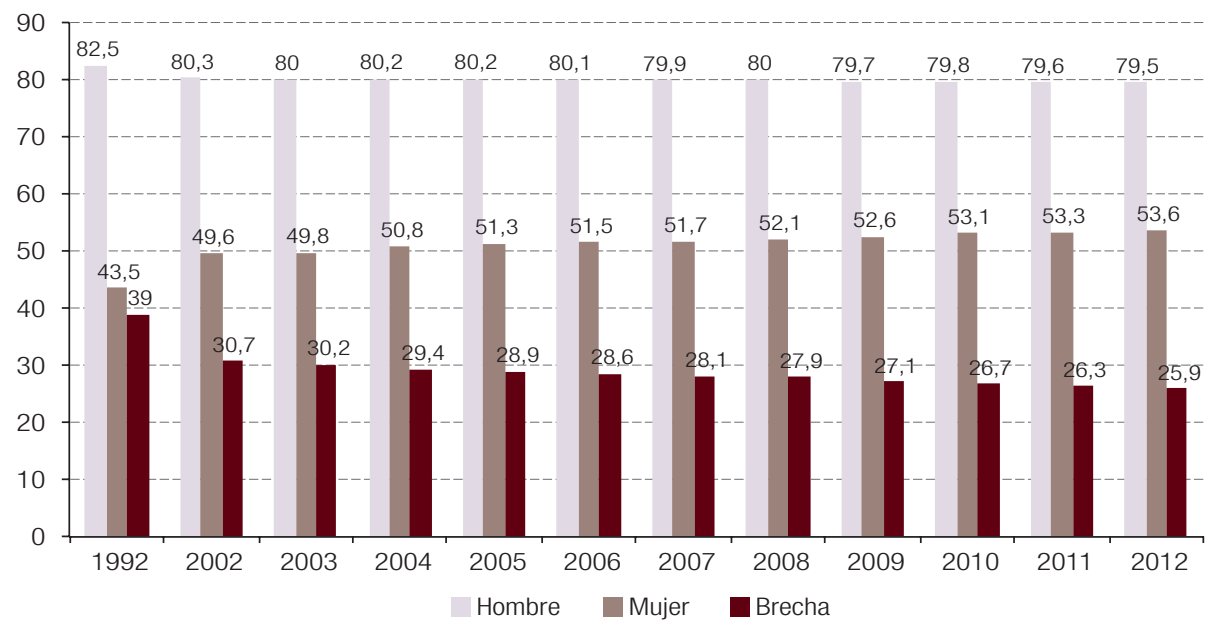

Fuente: Organización Internacional del Trabajo (OIT), “Indicadores clave del mercado de trabajo”, 2014 [en línea] http:// www.ilo.org/empelm/what/WCMS_114240/lang--en/index.htm.

\footnotetext{
2 Se refiere al porcentaje de la población económicamente activa (empleados y personas que buscan empleo) sobre la población en edad de trabajar (OIT, 2014a).
} 
De acuerdo con la OIT (2010), los factores determinantes del incremento en la tasa de participación femenina en la fuerza laboral son los siguientes: i) las normas sociales, culturales y religiosas; ii) el acceso a la educación y el nivel de ingresos; iii) la tasa de fertilidad; iv) la institucionalidad (marco legal, empresas); v) el sector principal en el que se basa la economía (agricultura, industria o servicios), y vi) el régimen político, la guerra y los conflictos. A partir del análisis del efecto de la fluctuación en el contexto económico a raíz de la crisis financiera, Pagés y Piras (2010) concluyen que el aumento de la participación femenina en la oferta laboral es producto de factores a largo plazo, como el incremento en el nivel educativo de las mujeres y la disminución en la tasa de fertilidad, entre otros. El incremento de la participación femenina en la fuerza laboral tiene repercusiones en el desarrollo económico de un país. Klasen y Lamanna (2009) encontraron que la inequidad de género en el empleo tiene un impacto negativo en el crecimiento económico. Asimismo, existe evidencia en diversos países de que el aumento de los ingresos controlados por las mujeres tiene un efecto importante en sus familias, pues los gastos se concentran en beneficio de sus hijos (Banco Mundial, 2012).

\section{Tasa de desempleo}

La tasa de desempleo se refiere a la población en edad de trabajar que no tenía trabajo y que a pesar de buscarlo no lo encontró (MTPE, 2014)3. A nivel mundial, la tasa de desempleo presentó una tendencia decreciente hasta el año 2007, pero aumentó en 2008 debido a la crisis financiera internacional (OIT, 2014b). Esta crisis incidió en la tasa de desempleo en todo el mundo, especialmente en las regiones donde la brecha de género en el desempleo era casi nula o incluso menor para las mujeres. En América Latina y el Caribe, la OIT (2013a) señala que, en promedio, la tasa de desempleo femenina supera a la de los hombres en una proporción de 1,35. La tasa de desempleo femenina ha sido superior a la de los hombres y esta situación no ha variado en las últimas dos décadas (véase el gráfico 2). No obstante la diferencia significativa, la disparidad de género se ha reducido en los últimos años.

\section{Gráfico 2}

América Latina y el Caribe (16 países): relación entre la tasa de desempleo de las mujeres y la tasa de desempleo de los hombres, 1990-2012

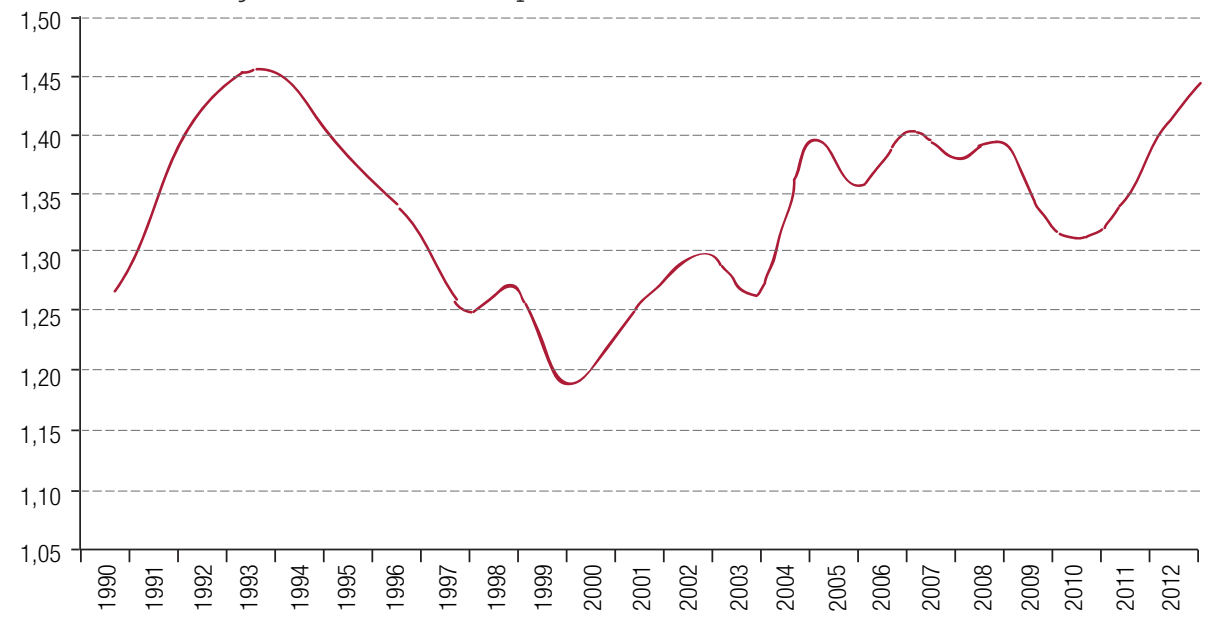

Fuente: Organización Internacional del Trabajo (OIT), Panorama laboral 2013. América Latina y el Caribe, Lima, Oficina Regional de la OIT para América Latina y el Caribe, 2013.

\footnotetext{
3 La población en edad de trabajar comprende a todas las personas aptas para el ejercicio de funciones productivas desde el punto de vista de la edad e incluye a toda la población mayor de 14 años (MTPE, 2014).
} 
Entre 2002 y 2012, la tasa de desempleo femenina en América del Sur se redujo en mayor medida que la tasa de desempleo masculina (véase el cuadro 1). Esta tendencia se traduce en una mayor participación de la mujer en el empleo y el acceso a los beneficios económicos que supone una participación activa en la fuerza laboral remunerada. Sin embargo, a pesar de estos avances, la tasa de desempleo femenina es aún mayor que la tasa de desempleo masculina. Según la OIT (2012), los factores que pueden explicar esta brecha son, entre otros, la mayor prevalencia del empleo temporal entre las mujeres, las diferencias en el nivel educativo obtenido, la segregación en el mercado laboral y la salida del mercado laboral por temas familiares (como la ausencia por el cuidado de los niños), que puede incidir en la empleabilidad de la mujer en un futuro reingreso.

\section{Cuadro 1}

América del Sur (países seleccionados): tasa de desempleo urbano de hombres y mujeres, 2002, 2003, 2011 y 2012

(En porcentajes)

\begin{tabular}{|c|c|c|c|c|c|}
\hline País & Género & 2002 & 2003 & 2011 & 2012 \\
\hline \multirow{2}{*}{ Argentina } & Hombre & 18,0 & 14,1 & 6,2 & 6,1 \\
\hline & Mujer & 17,6 & 18,7 & 8,5 & 8,8 \\
\hline \multirow{2}{*}{ Bolivia (Estado Plurinacional de) } & Hombre & 4,2 & & & \\
\hline & Mujer & 6,8 & & & \\
\hline \multirow{2}{*}{ Brasil } & Hombre & 7,3 & 7,8 & & 4,4 \\
\hline & Mujer & 11,5 & 12,3 & & 6,8 \\
\hline \multirow{2}{*}{ Chile } & Hombre & 8,6 & 7,9 & 6,1 & 5,4 \\
\hline & Mujer & 9,6 & 9,7 & 8,7 & 7,9 \\
\hline \multirow{2}{*}{ Colombia } & Hombre & 11,6 & 9,2 & & 9,4 \\
\hline & Mujer & 18,8 & 15,8 & & 13,2 \\
\hline \multirow{2}{*}{ Ecuador } & Hombre & 5,8 & 9,0 & & 4,5 \\
\hline & Mujer & 13,9 & 15,0 & & 5,5 \\
\hline \multirow{2}{*}{ Guyana } & Hombre & 20,9 & 21,2 & 17,2 & \\
\hline & Mujer & 29,2 & 28,5 & 25,7 & \\
\hline \multirow{2}{*}{ Paraguay } & Hombre & 8,9 & 6,6 & 4,4 & 6,7 \\
\hline & Mujer & 13,6 & 10,0 & 7,4 & 9,9 \\
\hline \multirow{2}{*}{ Perú } & $\underline{\text { Hombre }}$ & 8,3 & 9,0 & 5,8 & 5,4 \\
\hline & Mujer & 11,6 & 11,9 & 10,1 & 8,5 \\
\hline \multirow{2}{*}{ Suriname } & $\underline{\text { Hombre }}$ & 9,9 & & & \\
\hline & Mujer & 20,4 & & & \\
\hline \multirow{2}{*}{ Uruguay } & Hombre & 13,5 & 13,5 & 4,5 & 5,3 \\
\hline & Mujer & 21,2 & 20,8 & 7,7 & 8,1 \\
\hline \multirow{2}{*}{ Venezuela (República Bolivariana de) } & Hombre & 14,4 & 14,4 & 7,7 & 7,4 \\
\hline & Mujer & 18,8 & 20,3 & 9,3 & 9,0 \\
\hline
\end{tabular}

Fuente: Organización Internacional del Trabajo (OIT), “Indicadores clave del mercado de trabajo”, 2014 [en línea] http:// www.ilo.org/empelm/what/WCMS_114240/lang--en/index.htm.

\section{Tasa de ocupación}

Una tasa de ocupación más alta supone una mayor participación en actividades productivas remuneradas, que a su vez tienen mayor incidencia en el desarrollo económico (OIT, 2014c) ${ }^{4}$. No obstante, es necesario señalar que este indicador no distingue la calidad del trabajo desempeñado,

4 La tasa de ocupación se refiere a la proporción de personas ocupadas con respecto al total de la población; siendo las personas ocupadas aquellas que trabajan en una actividad económica (MTPE, 2014). 
de manera que se profundiza el análisis de la distribución de la población ocupada teniendo en cuenta las características del empleo.

La diferencia entre hombres y mujeres a nivel mundial se mantuvo constante hasta 2008, cuando la brecha de género aumentó como consecuencia de la crisis financiera internacional. Esto se debió a la contracción del mercado de trabajo y la desaceleración del crecimiento de la tasa de ocupación femenina en todas las regiones (OIT, 2012). En América del Sur, probablemente como consecuencia de la crisis financiera, se observa un estancamiento en la tasa de ocupación femenina en el año 2009. Sin embargo, esta se recupera a partir de 2010 y se mantiene la tendencia a la reducción de la brecha entre hombres y mujeres, debido a que la tasa de ocupación masculina creció en menor proporción con respecto a la femenina (OIT, 2013a).

Si bien un aumento de la tasa de ocupación significa mejoras en términos de oportunidad en el acceso al empleo, es necesario profundizar el análisis del tipo y la calidad de empleos a los cuales tiene acceso la mujer, pues este incremento podría concentrarse en el subempleo (ya sea por horas o por ingresos) o en empleos considerados vulnerables, categoría que comprende a los trabajadores familiares no remunerados y a los trabajadores autónomos (su remuneración depende directamente de los beneficios derivados de los bienes y servicios producidos) (División de Estadística de las Naciones Unidas/CEPAL, 2001)5. De acuerdo con la OIT (2012), más de la mitad del empleo femenino en 2012 correspondió a empleos vulnerables (autoempleo y trabajador familiar), caracterizados por largas horas de trabajo y condiciones desfavorables. También según la OIT (2010), la proporción de trabajadores asalariados no difiere significativamente entre hombres y mujeres a nivel mundial. En países como la Argentina, el Brasil, Colombia, Guyana, Suriname, el Uruguay y Venezuela (República Bolivariana de) se observa una mayor participación femenina (véase el gráfico 3). Es importante subrayar que en el trabajo asalariado se incluye tanto el empleo pleno como el subempleo por ingresos, por lo que este indicador se refiere a las personas que mantienen un ingreso fijo mensual, pero no se distingue si el ingreso es superior o inferior a la remuneración mínima vital.

En Bolivia (Estado Plurinacional de), el Ecuador, el Paraguay y el Perú, la tasa de autoempleo femenina supera a la tasa de autoempleo masculina. Al analizar la composición del autoempleo, se observa que la mayor parte de las mujeres se concentra en las categorías de trabajadores familiares y por cuenta propia (empleo vulnerable). De acuerdo con Otobe (2011), el empleo vulnerable se enmarca en la economía urbana informal y la economía rural y se caracteriza por escasa productividad, baja remuneración y falta de protección legal y social. Asimismo, las personas en trabajos familiares dependen de las relaciones de poder dentro de la familia para negociar sus condiciones laborales, de manera que la mayoría de las mujeres se encuentra en una posición subordinada (OIT, 2012).

Así, la mayor participación de la mujer en el mercado laboral no implica necesariamente que haya equidad en términos de calidad de empleo. Se observa que las mujeres tienen una mayor probabilidad de acceder a empleos clasificados como vulnerables (trabajadores por cuenta propia o trabajos familiares) y, a su vez, es menos probable que los trabajadores en empleos vulnerables tengan acuerdos formales de trabajo, por lo que no tendrían acceso a un sistema de seguridad social. Asimismo, el empleo vulnerable se caracteriza por ingresos inadecuados, baja productividad y condiciones de trabajo difíciles. Según datos de la OIT (2012), más de la mitad de las mujeres que trabajan a nivel mundial tiene un empleo vulnerable (50,4\%). Esto supone un mayor riesgo de pobreza e injusticia en el ámbito laboral para las mujeres, producto de un desequilibrio en la relación de empleador-trabajador (TUC Commission on Vulnerable Employment, 2008).

\footnotetext{
5 La Clasificación Internacional Uniforme de Ocupaciones distingue las siguientes categorías: trabajadores asalariados, trabajadores autoempleados y trabajadores familiares no remunerados. Dentro de los autoempleados se encuentran los empleadores, los trabajadores por cuenta propia y los miembros de cooperativas. El empleo vulnerable corresponde a los trabajadores por cuenta propia y a los trabajadores familiares (OIT, 2013b; División de Estadística de las Naciones Unidas/ CEPAL, 2001).
} 


\section{Gráfico 3}

América del Sur (países seleccionados): tasa de ocupación femenina y masculina, 2002 y 2010 (En porcentajes)

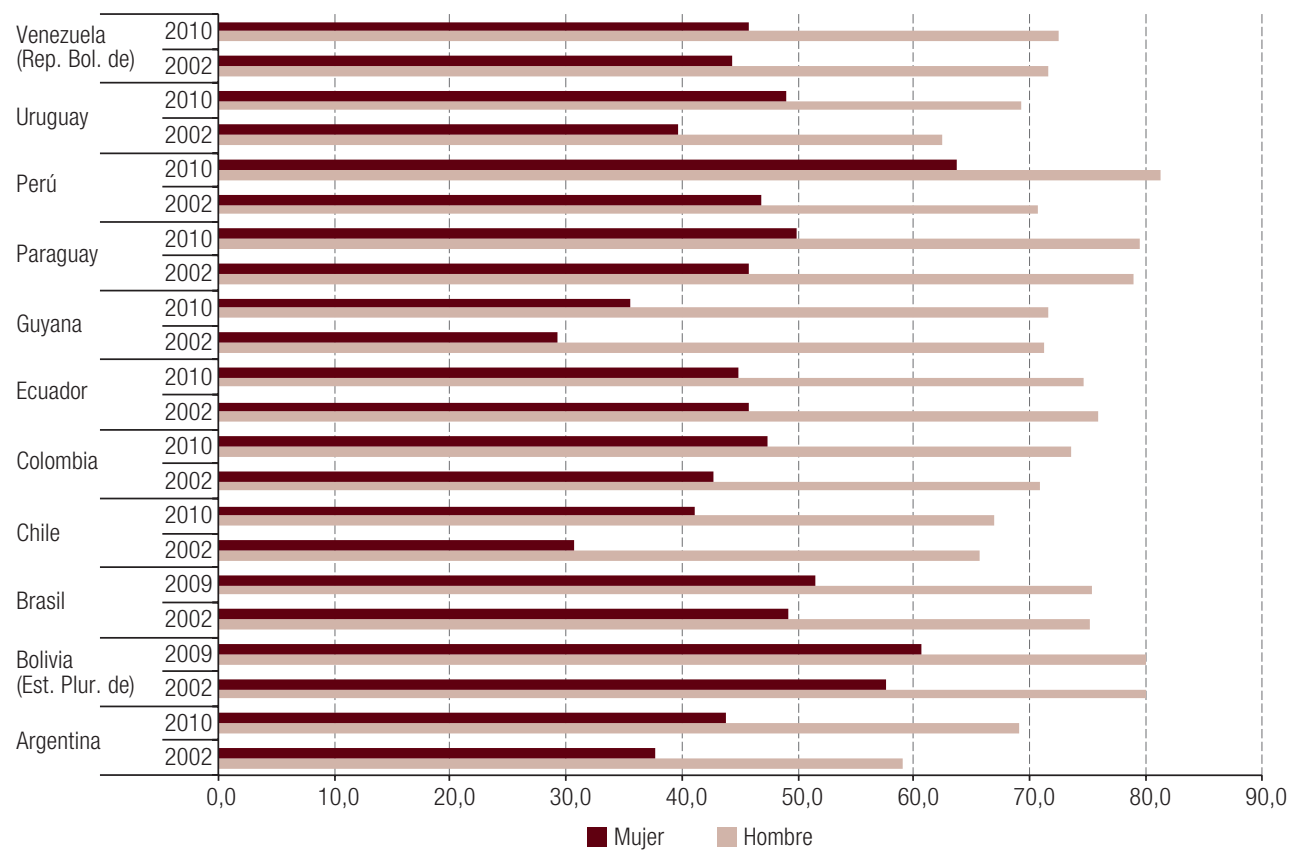

Fuente: Organización Internacional del Trabajo (OIT), "Indicadores clave del mercado de trabajo", 2014 [en línea] http:// www.ilo.org/empelm/what/WCMS_114240/lang--en/index.htm.

\section{Brecha salarial}

La brecha salarial de género es la diferencia en el ingreso medio de los hombres y las mujeres. El Foro Económico Mundial (2014) indica el ingreso estimado en dólares a paridad del poder adquisitivo (PPA) (véase el cuadro 2$)^{6}$. Con respecto a la razón del ingreso medio entre hombres y mujeres, los países sudamericanos que presentan mayor desigualdad son Guyana $(0,43)$, Suriname $(0,46)$ y la Argentina $(0,49)$. Por otra parte, la razón del ingreso entre mujeres y hombres del Estado Plurinacional de Bolivia es de 0,82 , lo que significa que la diferencia en el ingreso medio de hombres y mujeres es menor.

Ñopo (2012) encontró que en América Latina las mujeres tienen solo el 33\% de los empleos mejor pagados y que incluso en esos empleos existe una brecha salarial media del 58\%. A pesar de los avances en los últimos años, la brecha se reduce de manera lenta, probablemente debido a que las condiciones de acceso al mercado laboral de la mayoría de las mujeres son diferentes de las de los hombres, por lo general en empleos considerados vulnerables o en condición de subempleo (por horas o por salario), cuyas remuneraciones son inferiores a la media. Un ejemplo concreto es la alta tasa de subempleo de la mujer, que podría interpretarse como una elección por la flexibilidad de tiempo que le permite encargarse de responsabilidades familiares.

6 El dólar a paridad del poder adquisitivo es una medida que permite comparar los distintos niveles de vida de diferentes países. En esta conversión se utilizan tipos de cambio especiales que tienen en cuenta las diferencias en los precios de los productos de cada país. 


\section{Cuadro 2}

América del Sur (países seleccionados): ingreso medio y razón entre mujeres y hombres, 2013 (En dólares a paridad del poder adquisitivo)

\begin{tabular}{lccccccc}
\hline & \multicolumn{3}{c}{2006} & & \multicolumn{2}{c}{2013} \\
\cline { 2 - 3 } & Mujer & Hombre & Razón mujer/hombre & & Mujer & Hombre & Razón mujer/hombre \\
\hline Argentina & 6635 & 17800 & 0,70 & & 7987 & 16258 & 0,49 \\
\hline Bolivia (Estado Plurinacional de) & 1615 & 3573 & 0,45 & & 4750 & 5814 & 0,82 \\
\hline Brasil & 4704 & 10963 & 0,43 & & 9055 & 14857 & 0,61 \\
\hline Chile & 5753 & 14872 & 0,39 & & 14965 & 30513 & 0,49 \\
\hline Colombia & 4557 & 8892 & 0,51 & & 8163 & 13092 & 0,62 \\
\hline Ecuador & 1696 & 5569 & 0,30 & & 6579 & 12895 & 0,51 \\
\hline Guyana & - & - & - & & 2047 & 4708 & 0,43 \\
\hline Paraguay & 2316 & 7000 & 0,33 & & 4725 & 7526 & 0,63 \\
\hline Perú & 2231 & 8256 & 0,27 & & 8337 & 13532 & 0,62 \\
\hline Suriname & - & - & - & 5540 & 12159 & 0,46 \\
\hline Uruguay & 5763 & 10950 & 0,53 & & 11734 & 20644 & 0,57 \\
\hline Venezuela (República Bolivariana de) & 2890 & 6929 & 0,42 & & 9025 & 17896 & 0,5 \\
\hline
\end{tabular}

Fuente: Foro Económico Mundial, The Global Gender Gap Report 2014, Ginebra, 2013.

\section{Empleo del tiempo}

Las encuestas sobre el empleo del tiempo dan información sobre la manera en que las personas distribuyen su tiempo y aportan datos sobre la desigualdad en la distribución del trabajo no remunerado (Aguirre y Ferrari, 2014). Distintas organizaciones e instituciones internacionales y regionales, así como los propios gobiernos de los países latinoamericanos, reconocen la necesidad de profundizar la medición estadística del uso del tiempo en trabajo remunerado y trabajo no remunerado dentro de la región. De acuerdo con la CEPAL (2004), una de las explicaciones más importantes para comprender la persistencia de las desigualdades radica en que el mundo de la familia no ha cambiado y, por ende, no se ha fomentado la igualdad en la familia, el cuidado y la distribución del tiempo. Si bien las mujeres ingresan al mundo público, no han sido eximidas de las tareas del mundo privado y por eso desarrollan estrategias para optimizar el uso del tiempo. En consecuencia, este uso desigual del tiempo no es voluntario, sino que es asumido por la mujer como una imposición de su propio contexto social, debido - entre otras razones - a una serie de aspectos culturales inherentes a la idiosincrasia latinoamericana (CEPAL, 2010).

\section{Diferencias de género en la participación en el trabajo remunerado y no remunerado}

La división sexual del trabajo pone de relieve la asociación inmanente entre la mujer y la realización de actividades no remuneradas, que acentúa el desequilibrio social y económico de las sociedades latinoamericanas y limita su desarrollo en el mercado (Villamizar, 2011). Por consiguiente, la valoración y propalación del trabajo no remunerado es esencial para construir mejores políticas de inclusión social, teniendo en cuenta las diferencias de género e intragénero.

En el cuadro 3 se subraya el desequilibrio en la participación y el tiempo dedicado al trabajo remunerado y al trabajo no remunerado por parte de la población masculina y femenina. Debido a la diversidad de indicadores de medición resulta imposible establecer un balance regional. Sin embargo, en general, el porcentaje de participación de la mujer en el trabajo no remunerado es siempre mayor 
que el de sus pares varones y, en forma análoga, el tiempo dedicado por las mujeres a las actividades que no generan ingresos es invariablemente superior. Del mismo modo, el balance respecto de la carga total de trabajo se inclina a favor de la población masculina, aunque se reduce notablemente en el Brasil, donde la carga de trabajo diario de la mujer es solo 21 minutos mayor que la del hombre. Por el contrario, entre los países con mayor carga de trabajo sobresalen el Ecuador (20,3 puntos porcentuales), Colombia (10,8 puntos porcentuales) y el Perú (9 horas y 22 minutos semanales).

Cuadro 3

América del Sur (países seleccionados): tiempo dedicado al trabajo remunerado y no remunerado por sexo

(En horas y minutos y porcentaje de tiempo)

\begin{tabular}{|c|c|c|c|c|c|c|c|c|}
\hline \multirow{3}{*}{ País } & \multirow{3}{*}{ Año } & \multirow{3}{*}{ Período } & \multicolumn{6}{|c|}{ Tiempo dedicado } \\
\hline & & & \multicolumn{3}{|c|}{ Mujeres } & \multicolumn{3}{|c|}{ Hombres } \\
\hline & & & $\begin{array}{l}\text { Trabajo } \\
\text { remunerado }\end{array}$ & $\begin{array}{l}\text { Trabajo no } \\
\text { remunerado }\end{array}$ & $\begin{array}{l}\text { Carga total } \\
\text { de trabajo }\end{array}$ & $\begin{array}{l}\text { Trabajo } \\
\text { remunerado }\end{array}$ & $\begin{array}{l}\text { Trabajo no } \\
\text { remunerado }\end{array}$ & $\begin{array}{l}\text { Carga total } \\
\text { de trabajo }\end{array}$ \\
\hline Argentina & 2005 & Día & 02:45 & $04: 17$ & 07:02 & 05:14 & 01:33 & $06: 47$ \\
\hline $\begin{array}{l}\text { Bolivia (Estado } \\
\text { Plurinacional de) }\end{array}$ & 2001 & Día & $06: 42$ & $05: 06^{a}$ & $11: 48$ & 07:30 & $03: 18^{a}$ & $10: 48$ \\
\hline Brasil & 2009 & Día & $02: 45^{b}$ & $04: 14^{c}$ & 06:59 & $05: 12^{b}$ & $01: 26^{c}$ & 06:38 \\
\hline Chile & 2008 & Día & $07: 42$ & $04: 48$ & $12: 36$ & 09:00 & 02:48 & $11: 48$ \\
\hline Colombia & 2008 & Semana & $42: 24$ & $33: 18$ & $75: 42$ & $50: 24$ & $13: 30$ & $63: 54$ \\
\hline Ecuador & 2007 & Semana & $52,5 \%$ & $47,5 \%^{a}$ & $77: 03$ & $78,6 \%$ & $21,4 \%$ & $61: 56$ \\
\hline Paraguay & $\begin{array}{l}2009 \\
2010 \\
\end{array}$ & Día & 06:43 & 06:20 & $13: 03$ & 07:55 & $04: 42$ & $12: 37$ \\
\hline Perú & 2010 & Semana & $36: 25$ & $39: 28$ & $75: 53$ & $50: 38$ & $15: 53$ & 66:31 \\
\hline Uruguay & 2007 & Semana & $18: 42$ & $34: 48$ & $53: 30$ & $34: 36$ & $13: 24$ & 48:00 \\
\hline
\end{tabular}

Fuente: Elaboración propia, sobre la base de datos de encuestas nacionales e información estadística.

Nota: El uso del tiempo se distribuye en tres grupos de actividades: productivas remuneradas, productivas no remuneradas y actividades no productivas o personales. Las actividades productivas no remuneradas comprenden quehaceres del hogar, cuidado de personas, cuidado de menores de 15 años, cuidado de miembros del hogar de más de 60 años, servicios no remunerados para otros hogares, gestiones gratuitas para obtener servicios públicos y trabajo voluntario no remunerado en cuidado de la salud. Las actividades personales incluyen estudio y aprendizaje, convivencia social, aficiones, juegos y pasatiempos, deportes y ejercicio físico, comer, dormir, cuidados personales y uso de medios masivos de comunicación. En el cuadro se presentan solo las estadísticas de las actividades productivas remuneradas y no remuneradas.

a El trabajo no remunerado no comprende datos de trabajo voluntario o comunitario.

b El trabajo remunerado está asociado al trabajo voluntario, así como la búsqueda de trabajo.

c El trabajo voluntario o comunitario no está comprendido, solo actividades domésticas y cuidados de miembros de la familia.

En relación con las actividades no remuneradas, de los datos obtenidos surge que las que reciben mayor dedicación por parte de las mujeres son las actividades domésticas, seguidas por el cuidado de hijos e hijas y el cuidado de personas dependientes. Asimismo, resalta la dedicación al trabajo voluntario o comunitario. De la misma forma, la diferencia de tiempo más marcada en las actividades no remuneradas según el género corresponde a las actividades domésticas. La mayor diferencia se registra en el Perú, donde el tiempo semanal dedicado por la mujer a estas actividades sobrepasa por 16 horas y 38 minutos el tiempo dedicado por sus pares varones a la misma actividad. No obstante, se debe señalar que tanto en Chile como en el Perú, la dedicación masculina al trabajo voluntario o comunitario es mayor que la de sus pares femeninas (véase el cuadro 4). 


\section{Cuadro 4}

América del Sur (países seleccionados): tiempo dedicado a las actividades comprendidas en el trabajo no remunerado según el sexo

(En horas y minutos)

\begin{tabular}{|c|c|c|c|c|c|c|c|}
\hline \multirow[b]{2}{*}{ Países } & \multirow[b]{2}{*}{$\begin{array}{l}\text { Período de } \\
\text { encuesta }\end{array}$} & \multicolumn{3}{|c|}{ Mujeres } & \multicolumn{3}{|c|}{ Hombres } \\
\hline & & $\begin{array}{l}\text { Cuidado } \\
\text { de hijos }\end{array}$ & $\begin{array}{l}\text { Cuidado de } \\
\text { personas } \\
\text { dependientes }\end{array}$ & $\begin{array}{l}\text { Actividades } \\
\text { domésticas }^{\mathrm{a}}\end{array}$ & $\begin{array}{l}\text { Cuidado } \\
\text { de hijos }\end{array}$ & $\begin{array}{l}\text { Cuidado de } \\
\text { personas } \\
\text { dependientes }\end{array}$ & $\begin{array}{l}\text { Actividades } \\
\text { domésticas }^{\mathrm{a}}\end{array}$ \\
\hline Argentina & Día & $00: 58$ & & 03:03 & $00: 22$ & & 01:06 \\
\hline Brasil & Día & $02: 13$ & & $04: 10$ & $01: 39$ & & $02: 22$ \\
\hline Chile & Día & $02: 36$ & & 03:54 & $01: 30$ & & $02: 36$ \\
\hline Colombia & Semana & $26: 18$ & $22: 06$ & $24: 00$ & $14: 30$ & $13: 42$ & 09:30 \\
\hline Paraguay & Día & $04: 29$ & & & $02: 32$ & & \\
\hline Perú & Semana & $12: 14$ & $16: 47$ & $37: 28$ & $05: 49$ & 08:55 & $20: 50$ \\
\hline Uruguay & Semana & $17: 48$ & & $28: 36$ & $10: 06$ & & $12: 30$ \\
\hline
\end{tabular}

Fuente: Elaboración propia, sobre la base de datos de encuestas nacionales e información estadística.

${ }^{a}$ Las actividades domésticas se refieren estrictamente a las labores realizadas en beneficio del hogar.

\section{Participación de la mujer en cargos directivos y ejecutivos}

Las mujeres constituyen alrededor de 1.300 millones de los 3.300 millones $(39,9 \%)$ de personas que componen la fuerza laboral del mundo (OIT, 2012). La participación en la fuerza laboral asciende al $76,7 \%$ en el caso de los hombres y al 50,3\% en el de las mujeres a nivel mundial (OIT, 2014a). En América Latina y el Caribe, la participación de las mujeres en la fuerza laboral ha aumentado de manera progresiva y constante (al pasar del 43,5\% en 1992 al 49,6\% en 2002 y al 52,6\% en 2012), mientras que la participación masculina ha decrecido (del 82,5\% en 1992 al 80,3\% en 2002 y al 79,5\% en 2012) (OIT, 2012). Este incremento en la participación laboral femenina puede explicarse por el efecto combinado del desarrollo económico, el mayor nivel educativo, la disminución de las tasas de fertilidad, el desarrollo tecnológico - que permite disminuir el tiempo dedicado al cuidado del hogar - y cambios estructurales, que permiten reducir los costos de transacción y el uso del tiempo (Goldin, 2006). Sin embargo, las inequidades en el uso del tiempo todavía constituyen un factor crítico para la participación femenina en la fuerza laboral (OIT, 2012).

A pesar de esta mayor participación laboral de las mujeres, su desempeño en puestos de alta dirección y otros cargos de responsabilidad es bajo comparado con el de sus pares varones. Si bien las estadísticas son escasas, de acuerdo con la información proporcionada por Grant Thornton (2016), el promedio de mujeres en cargos de dirección empresarial en el mundo es del 24\%. Regionalmente, Europa del Este ocupa el primer puesto (35\%), seguida por África (27\%), los países emergentes de la región de Asia y el Pacífico (26\%), la Unión Europea (24\%), América del Norte (23\%) y América Latina (18\%).

En América Latina, la participación de las mujeres en puestos directivos va desde un 23\% en México a un 16\% en la Argentina. Además, el 53\% de las empresas de la región no cuentan con mujeres en sus equipos de dirección, un porcentaje muy por encima de la media mundial (32\%) (Grant Thornton, 2015b). El país de la región donde se registra el mayor porcentaje de empresas con mujeres en posiciones de alta dirección es la República Bolivariana de Venezuela (31\%), mientras que en Chile esas empresas representan solo un 5\% (Foro Económico Mundial, 2014) (véase el cuadro 5). 
Cuadro 5

América del Sur (países seleccionados): participación de las mujeres en posiciones directivas (En porcentajes)

\begin{tabular}{lccc}
\hline & $\begin{array}{c}\text { Empresas con mujeres en } \\
\text { posiciones ejecutivas }\end{array}$ & $\begin{array}{c}\text { Mujeres en directorio de } \\
\text { empresas cotizadas en bolsa }\end{array}$ & $\begin{array}{c}\text { Empresas con participación } \\
\text { femenina en su propiedad }\end{array}$ \\
\hline Argentina & 9 & 8 & 38 \\
\hline Bolivia (Estado Plurinacional de) & 22 & --- & 41 \\
\hline Brasil & 18 & 9 & 59 \\
\hline Chile & 5 & 5 & 30 \\
\hline Colombia & 12 & --- & 35 \\
\hline Ecuador & 17 & --- & 24 \\
\hline Guyana & 18 & --- & 58 \\
\hline Paraguay & 23 & --- & 52 \\
\hline Perú & 14 & 6 & 29 \\
\hline Suriname & 15 & --- & 18 \\
\hline Venezuela (República Bolivariana de) & 31 & --- & 31
\end{tabular}

Fuente: Foro Económico Mundial, The Global Gender Gap Report 2014, Ginebra, 2013.

Hay varios factores que dificultan la participación de más mujeres en los puestos de alta dirección en América Latina: i) aspectos culturales relacionados con la idea de que "el hombre es el jefe"; ii) horarios estrictos y frecuentes viajes inherentes a esos cargos, exigencias que solo pueden compensarse con un fuerte apoyo en el hogar para el cuidado de los hijos y las responsabilidades domésticas; iii) expectativas excesivas con respecto a las mujeres, debido a que no solo son juzgadas por su desempeño laboral, sino también por su aspecto, su vestimenta y su equilibrio entre el trabajo y la vida personal. Además, la escasa participación de las mujeres en posiciones ejecutivas podría estar relacionada con la desaceleración económica de los últimos años, que reduce las oportunidades de las mujeres para salir adelante, los viajes largos, que pueden representar una dificultad para las mujeres con niños o personas mayores a su cargo, el incremento en el costo de los servicios de cuidado de niños y la cultura machista (Grant Thornton, 2013).

\section{Principales barreras para el acceso de las mujeres a puestos de alta dirección}

Las barreras y obstáculos que enfrentan las mujeres para lograr puestos de alta dirección han sido objeto de diversos estudios. Eagly y Carli (2007) resumieron las principales barreras identificadas en la literatura para el ascenso de las mujeres en las empresas, a saber: i) el techo de cristal (glass ceiling); ii) la frontera de cristal (glass border); iii) el estilo personal y los estereotipos, y iv) los contactos y las redes. Esas autoras también resumieron los principales obstáculos al liderazgo empresarial de las mujeres encontrados en la literatura: i) prejuicios; ii) resistencia al liderazgo femenino; iii) demandas de la vida familiar; iv) falta de inversión en capital social, y v) estilos de liderazgo.

El techo de cristal se refiere a la idea de que existe una barrera invisible que detiene el progreso de las mujeres en las organizaciones, ya sea por factores culturales, estereotipos o actitudes frente al género femenino. La frontera de cristal sugiere que las mujeres no son promovidas a posiciones altas dentro de las organizaciones debido a su falta de experiencia internacional, pues a menudo se cree que las mujeres casadas no buscan la internacionalización de sus carreras y, por ello, no se invierte en su desarrollo. En la actualidad, la metáfora del techo de cristal se considera obsoleta para describir el ascenso de las mujeres, de manera que se la ha sustituido por la metáfora del laberinto, establecida 
por Eagly y Carli (2007). Un laberinto se define como "un lugar formado por calles y encrucijadas, intencionadamente complejo para confundir a quien se adentre en él". Esta imagen ilustra mejor la situación de las mujeres ejecutivas en el mundo laboral, pues aunque en teoría hombres y mujeres tienen igual acceso a los puestos ejecutivos, en la práctica estas tienen que enfrentar un viaje más complejo hacia su objetivo (véase el gráfico 4).

Gráfico 4

El laberinto de las mujeres ejecutivas

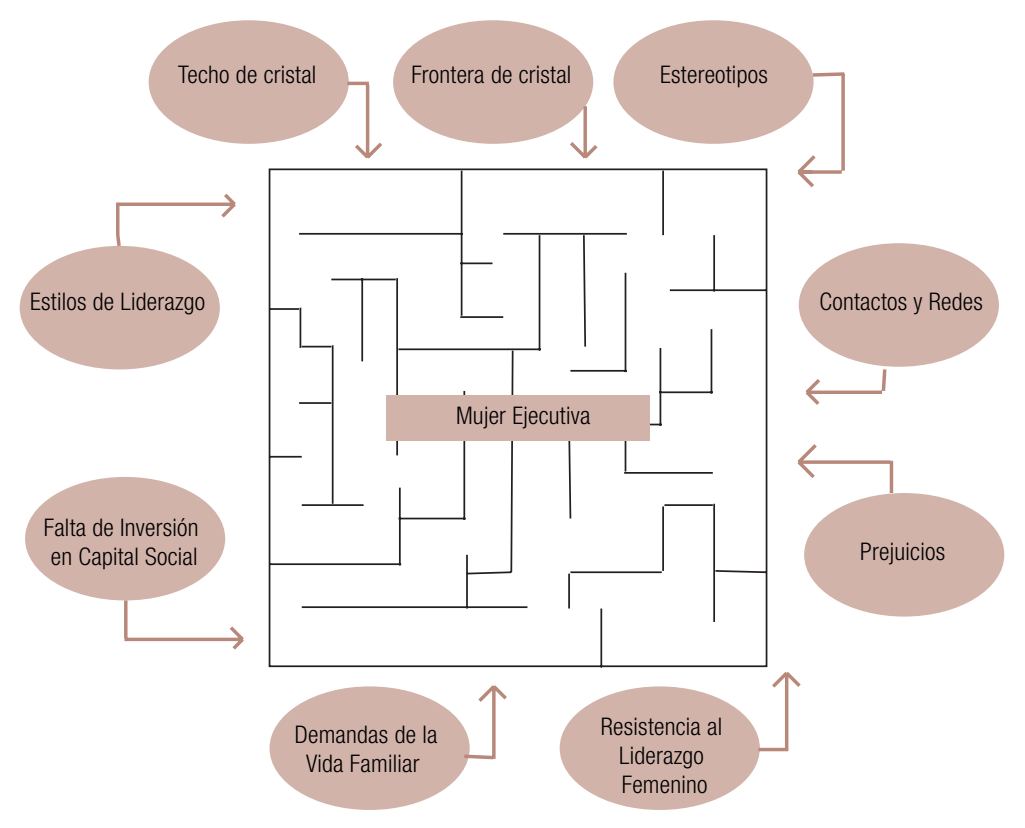

Fuente: Elaboración propia.

Respecto del estilo personal y los estereotipos, para las mujeres en cargos directivos es mucho más complicado encontrar un estilo personal de dirección que para los hombres, pues si una mujer se comporta como un colega hombre es posible que sea considerada agresiva, mientras que, si adopta una postura contraria será percibida como femenina. Los contactos y las redes son una potencial fuente de oportunidades laborales. Sin embargo, las mujeres en posiciones de alta dirección muchas veces se sienten solas en la cima de las organizaciones (al ser las únicas mujeres) y ello les dificulta crear y mantener contactos.

Los prejuicios frente al papel de liderazgo de la mujer aún persisten en parte de la población, porque considera que se rompe con el papel tradicional de liderazgo masculino. Estos prejuicios afectan directamente a las mujeres que tratan de abrirse camino para acceder a cargos de dirección en una empresa, pues a pesar de lograr un nivel semejante al de sus pares varones perciben salarios inferiores a ellos o ascienden en forma más lenta, no obstante sus calificaciones profesionales equivalentes. Sobre la resistencia al liderazgo femenino, según la tradición generacional, las características esperadas de un líder se asocian más con los hombres que con las mujeres. Los rasgos que se atribuyen a las mujeres incluyen ser amigables, sensibles, amables, caritativas, compasivas, mientras que los hombres suelen ser considerados asertivos, ambiciosos, agresivos y seguros de sí mismos. De este modo, a las mujeres se las relaciona con cualidades comunales y a los hombres con características de agente y, por lo general, las personas asocian a los líderes con estas últimas.

Sobre las demandas de la vida familiar, para la mayoría de las mujeres, las responsabilidades familiares constituyen una de las mayores barreras, dado que no existe una repartición equitativa de 
las tareas del hogar. Debido a que las mujeres llevan la mayor parte de la responsabilidad familiar, continúan siendo ellas quienes interrumpen sus carreras, toman más días libres o trabajan medio tiempo. Como resultado, tienen menos experiencia y acumulan menos horas de trabajo al año, lo cual conlleva un desarrollo más lento de su carrera profesional y una reducción de sus ingresos. Con respecto a la falta de inversión en capital social, se observa que los gerentes que avanzan más rápidamente en sus carreras invierten más tiempo y esfuerzo en socializar, politizar e interactuar con otros, mientras aquellos a quienes les toma más tiempo ascender se concentran en las típicas actividades de la administración: planificar, organizar, dirigir y controlar. Las diversas estadísticas sobre el uso del tiempo en actividades remuneradas y no remuneradas sustentan esta realidad.

\section{2. ¿Cómo incrementar la participación femenina en puestos ejecutivos?}

En diversos estudios se plantean propuestas orientadas a la sociedad, al Estado, a las organizaciones y a las propias mujeres para incrementar la participación femenina en los cargos gerenciales. Algunas de las propuestas para el Estado consisten en el establecimiento de legislación relacionada con la equidad de género o de cuotas femeninas en posiciones ejecutivas (Grant Thornton, 2015a). A la sociedad en general se recomienda modificar los estereotipos de liderazgo en las empresas, promover un cambio cultural para cambiar la noción de que el cuidado del hogar y de los hijos deben recaer exclusivamente en las mujeres y disminuir el nivel de exigencia que se impone a las mujeres líderes (Grant Thornton, 2015a).

Las principales propuestas para las empresas están relacionadas con: i) identificar los prejuicios hacia las líderes mujeres y trabajar para eliminarlos; ii) introducir cambios en las jornadas laborales, dando flexibilidad de horarios; iii) reducir la subjetividad de las evaluaciones de desempeño; iv) abrir los procesos de selección y no solo limitarse a personas recomendadas; v) asegurar una cantidad de posiciones representativa para las mujeres en la alta dirección; vi) mantener un equilibrio entre el número de hombres y mujeres en los equipos de trabajo; vii) ayudar a mejorar el capital social; viii) preparar a las mujeres para la alta dirección con asignaciones exigentes; ix) establecer políticas de recursos humanos que favorezcan la vida familiar; $\mathrm{x}$ ) brindar más tiempo para los ascensos a las personas que tienen una carga familiar significativa; xi) dar la oportunidad de integrarse a la organización a mujeres que dejaron el mundo laboral; xii) promover la participación de los hombres en los beneficios para mejorar la vida familiar (Eagly y Carli, 2007). Asimismo, Wirth (2012) plantea que las organizaciones deberían proporcionar ejemplos de buenas prácticas relativos a medidas y estrategias para promover a las mujeres, formular estrategias para promover a más mujeres a la dirección empresarial, diseñar políticas de igualdad de oportunidades y proporcionar directrices sobre sistemas de gestión de recursos humanos que tengan una dimensión de género. Por último, a las propias mujeres se les propone salir de su zona de confort, plantearse retos profesionales importantes y retar a sus organizaciones a evitar los sesgos de género (Grant Thornton, 2015a).

\section{Presencia de las mujeres en los directorios}

Es ampliamente reconocido que los directorios, como órganos de dirección de las empresas donde se toman las decisiones estratégicas, tienen un mejor desempeño cuando incluyen miembros con diferentes perspectivas, habilidades y experiencias profesionales. En algunos estudios se ha demostrado que hay un mayor crecimiento en el valor de mercado de las empresas europeas cuando existe una mayor proporción de mujeres en los equipos de alta dirección (McKinsey \& Company, 2007). Las empresas que contaban con más mujeres en los directorios presentaban un aumento del 
$42 \%$ en los rendimientos sobre las ventas y del $66 \%$ en los rendimientos de la inversión (Joy y otros, 2007). Más que a una cuestión de género, este efecto positivo se atribuye a que la contribución combinada de personas con diferentes habilidades y perspectivas, diferentes experiencias y estilos de vida permite una visión más holística de los problemas.

Según las cifras elaboradas por Governance Metrics International (2009), la participación de las mujeres en los directorios es todavía muy baja. Los datos disponibles muestran que algunos países de América del Sur tienen porcentajes de participación más bajos que Europa y América del Norte y semejantes a los de Asia (véase el cuadro 6). Esas proporciones ascienden al 11,3\% en Colombia, el 4,1\% en la Argentina, el 3,9\% en el Brasil, el 3,5\% en el Perú y el 2,4\% en Chile. El país que más destaca en el mundo es Noruega, el primero en establecer cuotas obligatorias de mujeres en los directorios en 2005 (el 40\% de hombres y el 40\% de mujeres en los directorios con más de 9 miembros), donde las mujeres actualmente representan el 35,6\% en los directorios (Governance Metrics International, 2009).

Cuadro 6

Países seleccionados: participación de las mujeres en los directorios (En porcentajes)

\begin{tabular}{lc}
\hline & Mujeres en directorios \\
\hline Países industrializados - Asia-Pacífico & 3,6 \\
\hline Países industrializados - Europa & 9,6 \\
\hline América del Norte & 11,4 \\
\hline Países emergentes - Asia & 4,7 \\
\hline Países emergentes - Europa & 7,8 \\
\hline Países emergentes - Oriente Medio y África & 12,4 \\
\hline Países emergentes - América Latina & 4,7 \\
\hline Argentina & 4,1 \\
\hline Brasil & 3,9 \\
\hline Chile & 2,4 \\
\hline Colombia & 11,3 \\
\hline Perú & 3,6 \\
\hline
\end{tabular}

Fuente: Governance Metrics International, "Women on Boards: A Statistical Review by Country, Region, Sector and Market Index", 2009 [en línea] http://www.boardagender.org/stats-reports/global/243-governance-metrics-internationalwomen-on-boards-a-statistical-review-by-country-region-sector-and-market-index-2009.

En el mundo existe interés en incrementar la participación femenina en la dirección de las empresas. En el cuadro 7 se resumen diferentes medidas tomadas en varios países, que pueden servir de referencia para su implementación en América del Sur. En algunos países se han establecido cuotas legales definidas por los gobiernos sobre el número de mujeres en los directorios y se considera que es la única forma de incrementar su participación. En otros se estima que el sistema de cuotas no es apropiado y que se requiere otro tipo de iniciativas. Algunos ejemplos de estas iniciativas incluyen la obligatoriedad para las empresas que cotizan en bolsas de valores de explicitar una política sobre la diversidad en sus juntas directivas, el establecimiento de procesos de contratación de mujeres con habilidades directivas, el incremento de la capacitación, educación y mentoría de las mujeres y la publicidad y promoción de estas posiciones (Deloitte, 2011). 


\section{Cuadro 7}

Iniciativas para promover la presencia femenina en los directorios

\begin{tabular}{|c|c|c|}
\hline País & Cuotas de género femenino & Otras iniciativas \\
\hline Francia & $\begin{array}{l}\text { Sí, obligatorias para empresas que } \\
\text { cotizan y no cotizan en bolsa }\end{array}$ & $\begin{array}{l}\text { A partir de 2017, la proporción de mujeres y hombres en los directorios no puede } \\
\text { ser inferior al } 40 \% \text { en las empresas que cotizan en bolsa o las grandes empresas } \\
\text { (ingresos o activos superiores a } 50 \text { millones de euros o más de } 500 \text { empleados). Si el } \\
\text { directorio incluye ocho personas o menos, la diferencia entre el número de directores } \\
\text { de cada género no puede ser mayor de } 2 \text {. Las empresas cotizadas en bolsa deben } \\
\text { alcanzar un primer objetivo del } 20 \% \text { de participación mínima de hombres y mujeres. }\end{array}$ \\
\hline
\end{tabular}

Bélgica Desde 2011 se prevé un mínimo de un tercio de directoras mujeres y un tercio mínimo para hombres

Noruega

España Sí

Sí

Países Bajos Sí

Malasia Sí

Sí
En mayo de 2009, el Ministerio de Igualdad de Oportunidades de la Región Flamenca, las Cámaras de Comercio y el Instituto Belga de Directores establecieron un programa para promover la representación de las mujeres en las juntas directivas de las empresas y en puestos de gestión. El programa incluye asistencia profesional a las iniciativas y el establecimiento de una base de datos pública de hombres y mujeres candidatos a directores.

Fue el primer país del mundo en introducir las cuotas en 2005, con aplicación obligatoria en 2008. Si los directorios tienen nueve miembros, debe haber cuatro directores de cada género. Si tienen más de nueve miembros, cada género debe representar el $40 \%$ de los directores (a partir de 2008 para empresas públicas). Si no se cumple, se disuelve la empresa.

En 2007, el Parlamento español aprobó una Ley de Igualdad que exige a las empresas que cotizan en bolsa nombrar un $40 \%$ de mujeres en sus directorios y hasta un $60 \%$ del total de miembros de la junta. Las empresas tenían plazo hasta 2015 para cumplir con esas cuotas, pero no se establecen penalidades en caso de incumplimiento.

El 27 de junio de 2011, el Primer Ministro de Malasia, Datuk Seri Razak, anunció que el Gobierno había aprobado una ley para promover la igualdad de género que obligaba a las empresas del sector privado a alcanzar por lo menos un $30 \%$ de representación femenina en los puestos de toma de decisiones. Las empresas tenían un plazo de cinco años para cumplir con el nuevo reglamento.

En diciembre de 2009, el Gobierno aprobó una enmienda legislativa que establecía cuotas de género para ejecutivos y miembros del consejo de vigilancia. En virtud de la enmienda, que fue consagrada en la legislación y entró en vigor el 1 de enero de 2012, se requiere que al menos el $30 \%$ de los miembros de los directorios sean mujeres y el $30 \%$ sean hombres. El plazo establecido para su cumplimiento era 2015 (empresas que cotizan en bolsa y grandes empresas).

Colombia Cuotas para la administración pública

Se requiere que un mínimo del $30 \%$ de los cargos de máximo nivel decisorio y otros niveles de decisión en las diferentes ramas y órganos de la administración pública sea desempeñado por mujeres.

Fuente: Deloitte, "Women in the Boardroom: A Global Perspective", 2011 [en línea] http://www.deloitte.com/assets/Dcomtanzania/Local\%20Assets/Documents/Deloitte\%20Article_Women\%20in\%20the\%20boardroom.pdf.

Si bien en los países de América del Sur no existen cuotas legales establecidas por los Gobiernos para la participación de las mujeres en los directorios de las empresas, en algunos de ellos se han implementado cuotas de género en materia electoral. Estas iniciativas pueden estar referidas a aspirantes (posibles candidatos electorales, usualmente de carácter voluntario por parte de los partidos políticos), candidatos (requerimientos mínimos de representación de ciertos grupos en la cédula de votación por mandato legal) o escaños reservados (número fijo de sitios entre los electos por mandato legal) (Dahlerup, 2006). En el cuadro 8 se muestran las cuotas de género en América del Sur. Se observa que no existen cuotas de escaños reservados, pero sí para el número de candidatos de género femenino. Resalta el caso de Colombia, donde se ha establecido que un mínimo del 30\% de los cargos de máximo nivel decisorio y de otros niveles de decisión en la administración pública sea desempeñado por mujeres (Ley 581, 2000). 


\section{Cuadro 8}

América del Sur (países seleccionados): cuotas de género en materia electoral

\begin{tabular}{lcccc}
\hline \multicolumn{1}{c}{ País } & $\begin{array}{c}\text { Cuotas voluntarias } \\
\text { adoptadas por los } \\
\text { partidos políticos }\end{array}$ & $\begin{array}{c}\text { Cuotas de candidatas } \\
\text { legisladas }\end{array}$ & $\begin{array}{c}\text { Escaños } \\
\text { reservados }\end{array}$ & $\begin{array}{c}\text { Mujeres en el } \\
\text { poder legislativo } \\
\text { (en porcentajes) }\end{array}$ \\
\hline Argentina & $X$ & $X$ & --- & $37(2013)$ \\
\hline Brasil & --- & $X$ & --- & $10(2014)$ \\
\hline Bolivia (Estado Plurinacional de) & $X$ & $X$ & --- & $53(2014)$ \\
\hline Chile & $X$ & -- & --- & $16(2013)$ \\
\hline Colombia & --- & $X$ & --- & $20(2014)$ \\
\hline Ecuador & --- & $X$ & --- & $39(2013)$ \\
\hline Paraguay & $X$ & $X$ & --- & $18(2013)$ \\
\hline Perú & --- & $X$ & --- & $22(2011)$ \\
\hline Uruguay & $X$ & $X$ & --- & $16(2014)$ \\
\hline Venezuela (República Bolivariana de) & --- & --- & --- & $17(2010)$ \\
\hline
\end{tabular}

Fuente: International IDEA/Universidad de Estcolomo/Unión Interparlamentaria, "Quota Database”, s/f [en línea] http:// www.quotaproject.org/.

\section{Hacia una sociedad de mujeres emprendedoras}

Promover la actividad empresarial es un aspecto prioritario de política pública debido a su relación con el crecimiento económico de los países, la generación de empleo y el desarrollo de los mercados. Pero ¿por qué interesarse en estudiar y comprender el emprendimiento femenino en particular? Entre otras cosas, promover la actividad empresarial de las mujeres ha cobrado particular importancia debido a su creciente participación en la actividad económica (Weeks y Seiler, 2001) y a que las mujeres presentan procesos y estilos organizacionales diferentes a los de los hombres, que es importante conocer para promover el emprendimiento (Neider, 1987). Además, si bien las actitudes empresariales de los hombres y las mujeres están influenciadas por varias de las mismas variables, la decisión de iniciar una empresa tiene un nivel de complejidad distinto para las mujeres que para los hombres (Minniti, Arenius y Langowitz, 2005). Las mujeres empresarias han sido identificadas como la principal fuerza para la innovación y la creación de empleo (OECD citado en Orhan y Scott, 2011, pág. 232).

\section{Qué se sabe de las mujeres empresarias}

Hasta el momento, la información y el conocimiento disponibles sobre la realidad de las mujeres dentro de las actividades emprendedoras son escasos. Los estudios realizados por el Global Entrepreneurship Monitor (GEM) de los Estados Unidos constituyen la información más completa disponible sobre la actividad empresarial de las mujeres en el mundo. GEM presenta las estadísticas de la tasa de actividad emprendedora (TAE) femenina y define el emprendimiento como "Cualquier intento de nuevos negocios o creación de nuevas empresas, tales como el autoempleo, la reorganización de un negocio o la expansión de un negocio existente por parte de un individuo, grupo de individuos o empresa ya establecida" (Serida y otros, 2005, pág. 13)․ . De acuerdo con el Global Report (Roland,

\footnotetext{
7 La TAE mide el porcentaje de adultos de 18 a 64 años que son propietarios de todo o parte de un negocio que tiene menos de 42 meses de existencia e incluye tanto a empresas nacientes como a empresas nuevas. Una empresa se considera naciente si las propietarias de todo o parte de un negocio declaran haber pagado remuneraciones por menos de 3 meses o haber tomado medidas concretas para poner en marcha un negocio. Una empresa se considera nueva si las propietarias de todo o parte de un negocio que dirigen activamente han pagado remuneraciones por más de 3 pero menos de 42 meses.
} 
Kelley y Kew, 2012), la TAE tiende a ser mayor en los países con menor producto bruto per cápita, como consecuencia de un mayor emprendimiento por necesidad económica. Asimismo, los países con mayor producto bruto presentan menores niveles de emprendimiento pero una mayor proporción de iniciativas emprendedoras basadas en la oportunidad.

Los resultados indican que la TAE femenina varía significativamente entre los 61 países estudiados, desde el $41 \%$ en Zambia hasta el 1\% en Suriname. En América Latina, la TAE femenina más alta se registra en el Ecuador (33\%), seguido por el Perú, Bolivia (Estado Plurinacional de) y Chile (véase el gráfico 5). En todos los casos, la TAE masculina supera a la femenina (Kelley y otros, 2015).

En el mismo estudio se analizan las motivaciones de las mujeres para convertirse en empresarias. El emprendimiento por oportunidad se refiere al número de personas que deciden iniciar un negocio o una empresa de su propiedad como una alternativa deseable de desarrollo de carrera y refleja el deseo de aprovechar una oportunidad empresarial. El emprendimiento por necesidad se refiere a las personas que inician negocios o empresas porque no tienen otras alternativas de empleo o, en caso de tenerlas, no son satisfactorias. Los resultados para América Latina son muy interesantes, puesto que en todos los países examinados hay más mujeres emprendedoras por oportunidad que por necesidad. La TAE por oportunidad asciende al 78\% en el Uruguay, al $71 \%$ en Chile y Bolivia (Estado Plurinacional de), al 69\% en el Perú, al 68\% en el Ecuador, al 61\% en el Brasil y al 59\% en Colombia y la Argentina (Kelley y otros, 2015).

\section{Gráfico 5}

Tasa de actividad emprendedora

(En porcentajes)

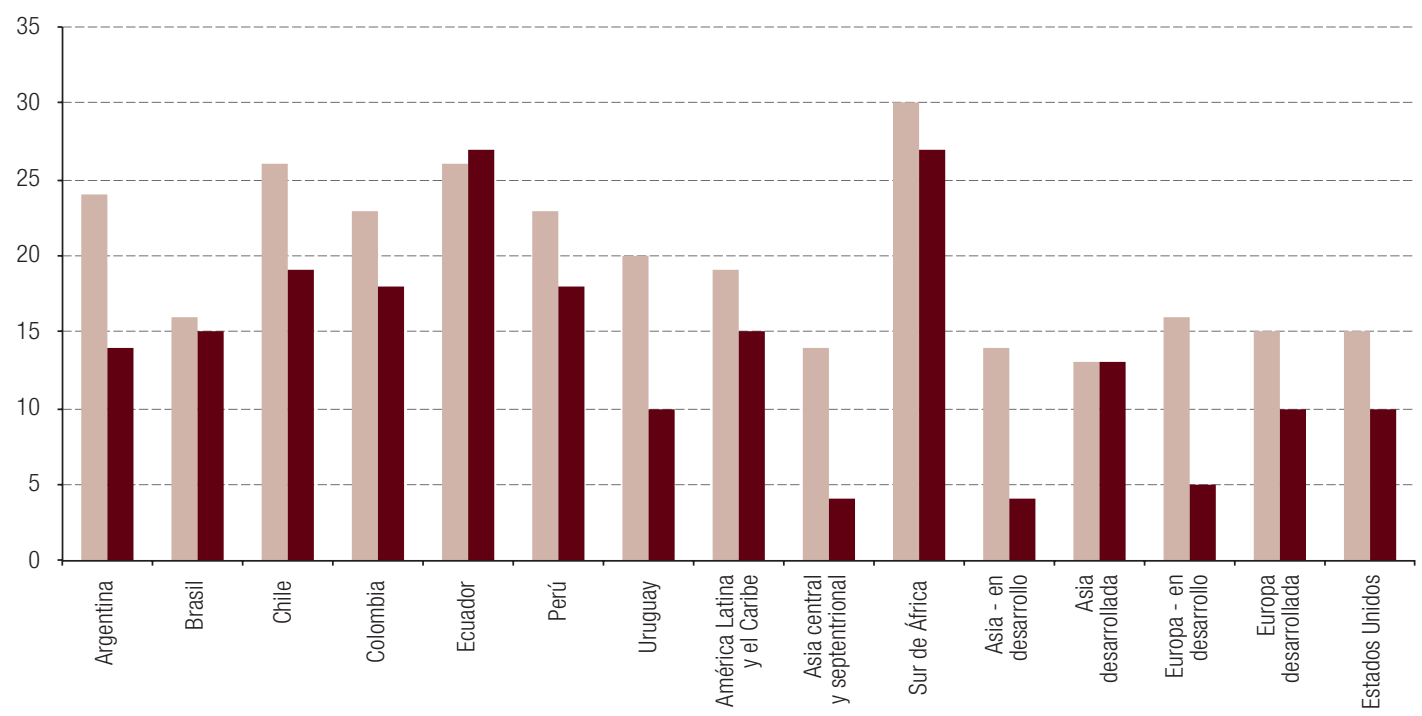


Gráfico 5 (conclusión)

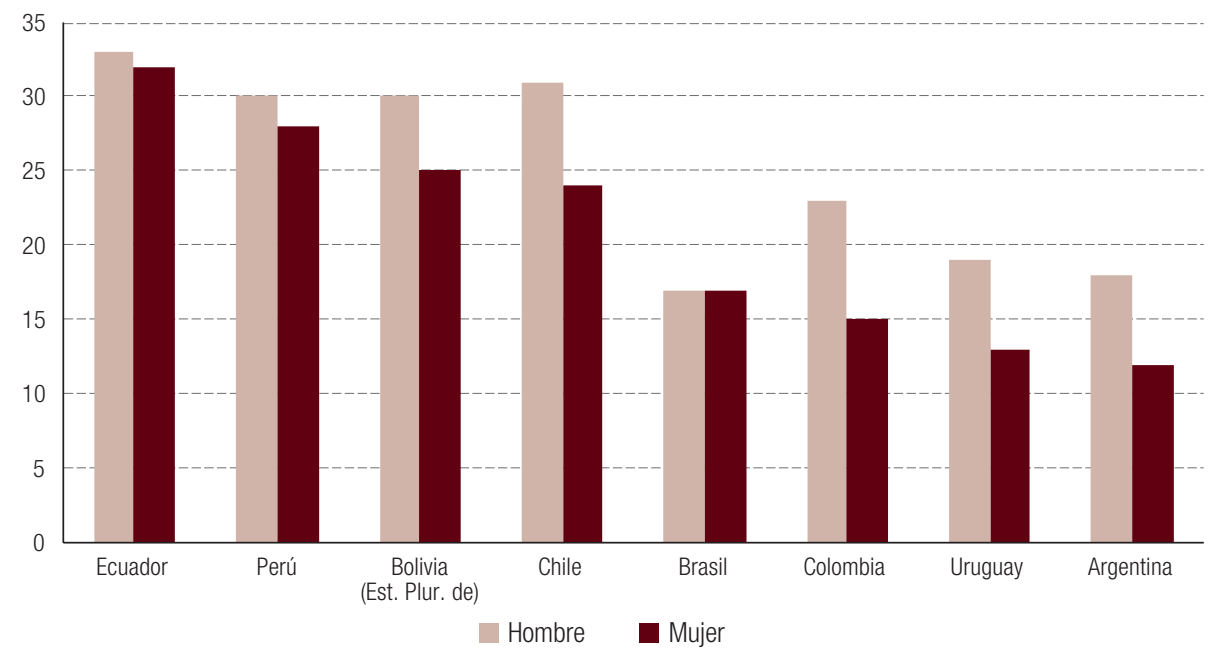

Fuente: D. Kelley y otros, Special Report. Women's Entrepreneurship, Global Entrepreneurship Monitor (GEM), 2015.

De acuerdo con la información disponible sobre las categorías ocupacionales en América del Sur en 2014, las mujeres empleadoras representaban el 2,7\% y los hombres el $6 \%$ (véase el cuadro 9). Los datos por país indican que la participación de las empleadoras en la fuerza de trabajo oscilaba entre un mínimo del 1,7\% al 2,3\% en Venezuela (República Bolivariana de), el Ecuador, el Uruguay y la Argentina y un máximo del 4,9\% en el Paraguay. Pese a que las empleadoras constituyen un grupo heterogéneo en empresas de diferentes tamaños, composición y origen, por lo general el emprendimiento femenino se concentra en las empresas con menos de cinco trabajadores (OIT, 2014d).

\section{Cuadro 9}

América del Sur (países seleccionados): población urbana ocupada como empleadores, 2014 (En porcentajes)

\begin{tabular}{|c|c|c|c|c|c|c|}
\hline & \multicolumn{3}{|c|}{ Mujeres } & \multicolumn{3}{|c|}{ Hombres } \\
\hline & $\begin{array}{l}\text { Establecimientos } \\
\text { con menos de } \\
\text { cinco trabajadores }\end{array}$ & $\begin{array}{l}\text { Establecimientos } \\
\text { con seis o más } \\
\text { trabajadores }\end{array}$ & Total & $\begin{array}{l}\text { Establecimientos } \\
\text { con menos de } \\
\text { cinco trabajadores }\end{array}$ & $\begin{array}{l}\text { Establecimientos } \\
\text { con seis o más } \\
\text { trabajadores }\end{array}$ & Total \\
\hline Argentina & 1,8 & 0,4 & 2,2 & 3,3 & 1,2 & 4,5 \\
\hline Bolivia (Estado Plurinacional de) & 3 & 0,8 & 3,8 & 6,3 & 2,6 & 8,9 \\
\hline Brasil & 1,9 & 0,9 & 2,8 & 3,4 & 1,8 & 5,2 \\
\hline Chile & 1,8 & 0,7 & 2,5 & 3,3 & 2,1 & 5,4 \\
\hline Colombia & 2,5 & 0,5 & 3,0 & 4,9 & 1,2 & 6,1 \\
\hline Ecuador & 1,7 & 0,4 & 2,1 & 3,3 & 1,5 & 4,8 \\
\hline Paraguay & 4 & 0,9 & 4,9 & 8,6 & 1,2 & 9,8 \\
\hline Perú & 2,9 & 0,3 & 3,2 & 5,3 & 1,2 & 6,5 \\
\hline Uruguay & 1,6 & 0,7 & 2,3 & 3,7 & 1,7 & 5,4 \\
\hline Venezuela (República Bolivariana de) & 1,3 & 0,4 & 1,7 & 3,5 & 1,2 & 4,7 \\
\hline Promedio & & & 1,7 & & & 4,7 \\
\hline
\end{tabular}

Fuente: Organización Internacional del Trabajo (OIT), Panorama laboral 2014. América Latina y el Caribe, Lima, Oficina Regional de la OIT para América Latina y el Caribe, 2014.

Si bien la información es incompleta, estos datos muestran la importancia de la actividad empresarial de las mujeres en América del Sur. Sin embargo, todavía se sabe muy poco sobre ellas. 
Para poder diseñar programas y políticas de apoyo dirigidos a las mujeres, es prioritario entender cabalmente el fenómeno del emprendimiento femenino.

\section{El perfil de las mujeres empresarias}

Debido a que la actividad emprendedora supone personas capaces de identificar oportunidades y dispuestas a asumir más riesgos que las demás, es muy importante analizar las motivaciones y los estímulos que las llevan al emprendimiento. Tradicionalmente, estas motivaciones se han caracterizado conforme al modelo de vocación o necesidad económica. Sin embargo, Avolio (2008) sostiene que ese modelo es muy simple para caracterizar a las mujeres empresarias en América Latina.

Al estudiar a las mujeres empresarias en el Perú, Avolio (2008) encontró que presentan un perfil demográfico, educativo y laboral variado y no conforman un grupo homogéneo, por lo que no deberían considerarse una categoría única como usualmente ocurre en los programas de apoyo empresarial destinados a ellas. De acuerdo con Avolio (2008), los programas de apoyo y respaldo a la actividad empresarial de las mujeres deberían empezar con un diagnóstico que reconozca la diversidad de sus antecedentes. La autora propone un marco conceptual que explica el perfil de las mujeres empresarias a partir de la etapa de los ciclos de vida laboral y personal en que optan por el emprendimiento (dado que las mujeres inician sus empresas en diferentes momentos de su vida y esto afecta el tipo de negocio y su particular acercamiento a la propiedad de empresas) y los factores que las han estimulado a optar por la actividad empresarial. En su estudio identifica seis perfiles de mujeres empresarias, que expresan las diferentes rutas por las que las mujeres llegan al emprendimiento, denominados de la siguiente manera: mujeres jóvenes con opción laboral, mujeres en crecimiento con limitaciones externas, mujeres consolidadas con carrera trunca, mujeres jóvenes naturales, mujeres en crecimiento en desarrollo y mujeres consolidadas de fin de carrera.

Asimismo, Avolio (2008) encontró que las mujeres empresarias presentan diversos antecedentes educativos y que el tipo de experiencia educativa previa al emprendimiento no parece ser un factor determinante en la naturaleza de la empresa propiedad de mujeres. Con respecto a los antecedentes laborales, en el mismo estudio se encontró que en general las empresarias cuentan con experiencia laboral de diverso tipo y en diversos sectores antes de iniciar su emprendimiento y que la decisión de crear una empresa estaría influenciada por la experiencia laboral previa o por aficiones personales. En relación con los antecedentes familiares, el estudio indica que la actividad laboral de los padres parece incidir en la decisión de realizar el emprendimiento, dado que las mujeres empresarias con frecuencia provienen de familias cuyos padres han estado relacionados con el emprendimiento, actividades laborales independientes o el autoempleo.

En el mismo estudio se establece que las mujeres consideran importante el apoyo económico y emocional que reciben para desarrollar sus empresas, que proviene principalmente de sus esposos o parejas y familiares. Los principales obstáculos que las mujeres suelen enfrentar son propios de la actividad empresarial y no particulares de su género. Sin embargo, el principal obstáculo de género para las empresarias es la división tradicional de los papeles en el hogar, que atribuye a la mujer la responsabilidad principal en el cuidado de los hijos y del hogar a la par que realiza un trabajo económicamente productivo, dados los fuertes patrones culturales con respecto al papel de la mujer en la sociedad. Esto exige que las mujeres empresarias atiendan las demandas del hogar en mayor medida que los hombres y desempeñen simultáneamente una diversidad de tareas, algo que puede generar tensiones en el empleo de su tiempo o conflictos entre sus papeles de madre y empresaria.

Heller (2010) encontró que, en general, las mujeres emprendedoras en América Latina se concentran en las zonas urbanas en la mayoría de los países de la región, son casadas o convivientes y tienen niveles educativos altos. Casi la mitad de ellas (46\%) tiene entre 30 y 45 años, mientras que 
la participación de jóvenes menores de 30 años (16\%) sugiere un potencial de emprendimientos a futuro. La gran mayoría (70\%) son dueñas o socias de microempresas (establecimientos de hasta seis trabajadores) y, en menor proporción, pequeñas y medianas empresas. Se concentran sobre todo en sectores relacionados con los servicios y el comercio, hotelería y restaurantes. Las principales dificultades que experimentan son: falta de experiencia empresarial y en comercialización, insuficiente formación empresarial específica (administración y mercadotecnia), barreras en el acceso a fuentes de crédito y financiamiento, obstáculos en el acceso a redes de comercialización y excesivos trámites y procedimientos para crear las empresas (pág. 35).

De acuerdo con Daeren (2000), las empresarias latinoamericanas dedican más de 48 horas semanales de su tiempo al trabajo empresarial y en su gran mayoría son dueñas o socias de micro, pequeñas y medianas empresas (aunque en menor proporción). Su estrategia empresarial se caracteriza por su apertura a las innovaciones y menos en cuanto a innovaciones tecnológicas. Sienten gran satisfacción por su labor, el estímulo de la familia y del esposo constituye un factor clave para su desarrollo como empresarias. Sus principales dificultades son: falta de experiencia empresarial, insuficiente formación empresarial específica, escasa actualización e información en temas económicos y financieros, barreras en el acceso a fuentes financieras, barreras en el acceso a redes de comercialización, falta de confianza en sí mismas y responsabilidades familiares como fuente constante de preocupación y estrés.

\section{Programas para el desarrollo empresarial femenino}

Si bien existe una serie de iniciativas gubernamentales o privadas encargadas de promover la actividad empresarial femenina en la región, sus efectos no se han evaluado sistemáticamente en muchos casos (véase el cuadro 10). Entre estas iniciativas destacan el programa Mujer Emprende, ejecutado por el Servicio Nacional de la Mujer (SERNAM), organismo creado en 1991 por el Gobierno de Chile para promover la igualdad de oportunidades entre hombres y mujeres y contribuir al emprendimiento femenino, generando redes y alianzas que fortalezcan y desarrollen las capacidades emprendedoras de las mujeres; la Asociación Mujeres Emprendedoras en Chile, una comunidad de mujeres que colaboran, apoyada por profesionales que las acompañan en el desarrollo de negocios en el tiempo; y el Servicio Brasileño de Apoyo a las Micro y Pequeñas Empresas (SEBRAE), una organización brasileña dedicada a la promoción del emprendimiento y a comprender las características económicas y demográficas de las mujeres empresarias.

Cuadro 10

América del Sur (países seleccionados): programas de promoción de la actividad emprendedora femenina

\begin{tabular}{clll}
\hline \multicolumn{1}{c}{ País } & \multicolumn{1}{c}{ Programa } & \multicolumn{1}{c}{ Descripción y objetivos } & Sitio web \\
\hline Comunidad de Mujeres & $\begin{array}{l}\text { Organización integrada por mujeres cuya misión es brindar } \\
\text { herramientas de formación y desarrollo a las mujeres de } \\
\text { la ciudad de Rosario y la región, para que optimicen sus } \\
\text { recursos personales y profesionales y puedan desarrollar } \\
\text { de manera exitosa su carrera emprendedora y los proyectos } \\
\text { sociales y comerciales que lideran. }\end{array}$ & emprendedorascriar.org \\
Argentina & $\begin{array}{l}\text { Organización que promueve el empresariado femenino } \\
\text { Argentina de Mujeres } \\
\text { Empresarias (OAME) }\end{array}$ & $\begin{array}{l}\text { mediante la interacción de sus asociadas, la capacitación } \\
\text { constante y el desarrollo de planes organizacionales. }\end{array}$ & oame.org.ar \\
\cline { 2 - 4 } & $\begin{array}{l}\text { Asociación } \\
\text { lberoamericana } \\
\text { de Mujeres } \\
\text { Empresarias (AIME) }\end{array}$ & $\begin{array}{l}\text { Organización no gubernamental (ONG) pluralista, con la } \\
\text { voluntad de apoyar y promover el desarrollo pleno de la } \\
\text { mujer su condición de empresaria y en respuesta a } \\
\text { una demanda de la mujer que reclama un ámbito donde } \\
\text { potenciar, desde su propia identidad, un aporte al mundo } \\
\text { empresarial. }\end{array}$ & aime.org.ar \\
\hline
\end{tabular}


Cuadro 10 (continuación)

\begin{tabular}{|c|c|c|c|}
\hline País & Programa & Descripción y objetivos & Sitio web \\
\hline $\begin{array}{l}\text { Bolivia (Estado } \\
\text { Plurinacional de) }\end{array}$ & $\begin{array}{l}\text { Red Nacional } \\
\text { de Mujeres } \\
\text { Emprendedoras }\end{array}$ & $\begin{array}{l}\text { Red integrada por emprendimientos económicos } \\
\text { unipersonales o familiares y asociativos, compuestos y } \\
\text { encabezados por mujeres. Estos emprendimientos pertenecen } \\
\text { a rubros de producción, transformación y servicios. } \\
\text { Asimismo, se busca fortalecer la red organizacional en } \\
\text { cada departamento del país mediante asesorías técnicas } \\
\text { y capacitación en temas orientados a los negocios, brindar } \\
\text { vías de acceso a mercados y aumentar la incidencia política } \\
\text { de las acciones. }\end{array}$ & \\
\hline \multirow[b]{2}{*}{ Brasil } & $\begin{array}{l}\text { Asociación de Mujeres } \\
\text { Emprendedoras del } \\
\text { Brasil (AMEBRAS) }\end{array}$ & $\begin{array}{l}\text { Asociación de mujeres que busca promover la realización } \\
\text { de proyectos de emprendimientos femeninos en Río de } \\
\text { Janeiro por medio de capacitación técnica. }\end{array}$ & amebras.org.br \\
\hline & $\begin{array}{l}\text { Organización Brasileña } \\
\text { de Mujeres Empresarias }\end{array}$ & $\begin{array}{l}\text { ONG derivada de la Asociación Mundial de Ejecutivas de } \\
\text { Empresa que brinda apoyo en la planificación y ejecución } \\
\text { de negocios sociales y acciones filantrópicas. Su objetivo } \\
\text { es la generación de mayores recursos, para fijar referentes } \\
\text { en la creación de valor y el desarrollo sostenible. }\end{array}$ & obme.org.br \\
\hline
\end{tabular}

Mujeres

Emprendedoras mujeres que ya son emprendedoras o desean emprender y capacitarse a poner sus ideas en práctica. Para ello se les brinda orientación, asesoría y apoyo respecto de los intangibles necesarios y se las incorpora a una red importante.

Organización integrada por más de 3.000 empresarias, emprendedoras y ejecutivas que apoyan la gestión empresarial de la mujer, liderando a las empresarias, profesionales y emprendedoras a través de una gran e innovadora red de contactos que facilita su inclusión en el mundo económico y de los negocios.

Mujeres Empresarias (ME)

Asociación que deriva de la Confederación Gremial Nacional

Asociación Gremial

de la Mujer Micro,

Pequeña y Mediana

Empresaria

(EmpreMujer)

Unida de la Mediana y Pequeña Industria, Servicios y Artesanado de Chile (CONUPIA), que representa a los empresarios desde Arica a Punta Arenas.

mujeresemprendedoras.c

El Programa Emprendimiento corresponde a diversas estrategias de intervención que permiten mejorar las condiciones para el desarrollo exitoso de emprendimientos

Programa Emprendimiento de SERNAM encabezados por mujeres. Combina una coordinación nacional destinada a generar acciones de emprendimiento en todo el país y una gestión local institucional proactiva, con el fin de contribuir a la construcción de un escenario favorable para la inclusión de las mujeres en el ámbito del trabajo independiente. me.cl

empremujer.cl

portal.sernam. $\mathrm{cl} / ? \mathrm{~m}=$ programa\& $\mathrm{i}=6$

\begin{tabular}{|c|c|c|c|}
\hline \multirow{2}{*}{ Colombia } & $\begin{array}{l}\text { Asociación Nacional de } \\
\text { Mujeres Empresarias } \\
\text { y Emprendedoras } \\
\text { de Colombia (Col } \\
\text { Empresarias) }\end{array}$ & $\begin{array}{l}\text { ONG que reúne a las mujeres empresarias de Colombia } \\
\text { que desarrollan diferentes actividades en los sectores } \\
\text { económicos y sociales en diferentes regiones del país. } \\
\text { Su objetivo es ayudar a desarrollar los emprendimientos } \\
\text { o negocios de las mujeres colombianas. }\end{array}$ & colempresarias.org \\
\hline & $\begin{array}{l}\text { Fundación Mujeres } \\
\text { por Colombia }\end{array}$ & $\begin{array}{l}\text { Organización que contribuye para que las mujeres } \\
\text { profesionales lideren la transformación de Colombia hacia } \\
\text { la paz, la justicia, la equidad y el desarrollo al empoderarse } \\
\text { y formar parte de las instancias decisorias políticas, } \\
\text { económicas y sociales del país. }\end{array}$ & fundacionmujeresporcolombia.org \\
\hline Ecuador & $\begin{array}{l}\text { Asociación } \\
\text { lberoamericana } \\
\text { de Empresarias } \\
\text { (AIME - Loja) }\end{array}$ & $\begin{array}{l}\text { ONG integrada por ejecutivas, empresarias y emprendedoras } \\
\text { que buscan asesorar, capacitar e integrar a empresarias o } \\
\text { emprendedoras que quieran desarrollarse a nivel personal } \\
\text { y profesional. }\end{array}$ & Sin información \\
\hline
\end{tabular}


Cuadro 10 (conclusión)

\begin{tabular}{|c|c|c|c|}
\hline País & Programa & Descripción y objetivos & Sitio web \\
\hline Paraguay & $\begin{array}{l}\text { Asociación Paraguaya } \\
\text { de Empresarias, } \\
\text { Ejecutivas y } \\
\text { Profesionales (APEP) }\end{array}$ & $\begin{array}{l}\text { Asociación de mujeres empresarias, ejecutivas y } \\
\text { emprendedoras que buscan el desarrollo empresarial de } \\
\text { las mujeres paraguayas. }\end{array}$ & apep.org.py \\
\hline \multirow{2}{*}{ Perú } & $\begin{array}{l}\text { Organización } \\
\text { Internacional de } \\
\text { Mujeres en Negocios } \\
\text { (OWIT Perú) }\end{array}$ & $\begin{array}{l}\text { Asociación que agrupa a mujeres profesionales } \\
\text { emprendedoras, ejecutivas y empresarias cuyo objetivo } \\
\text { es promover el desarrollo de la mujer en el mundo del } \\
\text { trabajo, fomentando un cambio en la sociedad peruana, } \\
\text { hacia una cultura de éxito y responsabilidad social. }\end{array}$ & owitperu.org \\
\hline & $\begin{array}{l}\text { Asociación de Mujeres } \\
\text { Batalla (AMUBA) }\end{array}$ & $\begin{array}{l}\text { ONG integrada por ejecutivas, empresarias y emprendedoras } \\
\text { sociales provenientes de distintos ámbitos, cuyo objetivo } \\
\text { es ayudar a las mujeres y jóvenes de escasos recursos } \\
\text { a alcanzar la realización personal mediante el desarrollo } \\
\text { de planes de negocios. }\end{array}$ & amubaperu.com \\
\hline $\begin{array}{l}\text { Venezuela } \\
\text { (República } \\
\text { Bolivariana de) }\end{array}$ & $\begin{array}{l}\text { Asociación Venezolana } \\
\text { de Mujeres (AVM) }\end{array}$ & $\begin{array}{l}\text { Asociación que invita a las mujeres de escasos recursos } \\
\text { a formarse como emprendedoras. El objetivo es dar a la } \\
\text { mujer venezolana las herramientas necesarias para mejorar } \\
\text { su calidad de vida y la de su familia. }\end{array}$ & $\begin{array}{l}\text { asociacionvenezolanademujeres. } \\
\text { com.ve }\end{array}$ \\
\hline
\end{tabular}

Fuente: Elaboración propia.

Asimismo, en algunos países de la región existen ministerios o dependencias encargados de promover la equidad de género y el empleo femenino. En marzo de 2014, Chile emitió un decreto para la creación del Ministerio de la Mujer y la Equidad de Género, mientras que el Paraguay cuenta con el Ministerio de la Mujer, el Perú con el Ministerio de la Mujer y Poblaciones Vulnerables, Venezuela (República Bolivariana de) con el Ministerio del Poder Popular para la Mujer e Igualdad de Género (antes Ministerio de la Familia) y el Brasil con una Secretaría de Políticas para las Mujeres. En este último país también se creó como medida provisoria el Ministerio de las Mujeres, Igualdad Racial y Derechos Humanos en octubre de 2015. En el caso de la Argentina, Bolivia (Estado Plurinacional de), Colombia, el Ecuador y el Uruguay no se han dado estas iniciativas.

\section{Algunas propuestas para el desarrollo de las empresas de mujeres}

Sobre la base de la revisión bibliográfica, se realizan las siguientes recomendaciones prácticas orientadas a estimular las capacidades de las mujeres, disminuir los obstáculos que enfrentan y así aumentar las probabilidades de éxito de sus iniciativas empresariales:

i) Establecer estadísticas nacionales sobre la actividad empresarial que incluyan información sobre los aspectos de género.

ii) Desarrollar programas de apoyo específicos para las mujeres empresarias, que tengan en cuenta sus necesidades particulares.

iii) Elaborar un programa formal de "empresarias mentoras", en el que mujeres empresarias ofrezcan mentoría a mujeres que recién inician la actividad empresarial.

iv) Incluir, a partir de la experiencia de programas desarrollados en otros países, las siguientes áreas en los programas orientados a estimular el emprendimiento en las mujeres empresarias: asesoramiento y consultoría, capacitación en la gestión de empresas, financiamiento, acceso a información y red de contactos. 
v) Mejorar las habilidades de las mujeres en la gestión de empresas, por medio de la capacitación en temas específicos y el desarrollo de la capacidad de reunir el capital humano necesario para promover sus empresas.

vi) Capacitar a las mujeres para que puedan reconocer sus propias debilidades y contratar a las personas que requieren en las áreas que ellas no conocen.

vii) Facilitar el acceso al crédito mediante programas de financiamiento, simplificar el sistema de garantías exigidas y, sobre todo, reducir los costos de los créditos para las mujeres empresarias.

viii) Facilitar el acceso a información sobre mercados, nuevos productos, desarrollo de negocios y gestión mediante programas específicos, con miras a ampliar las oportunidades de negocios de las mujeres.

ix) Establecer redes de contactos que permitan a las mujeres intercambiar experiencias con empresarios y organizaciones profesionales y aumentar la oportunidad de generar empresas y, a su vez, sirvan como fuente de inspiración. La red de contactos y el acceso a información exponen a las mujeres a un ambiente de negocios más amplio y les permiten acceder a oportunidades para aumentar su propio potencial como empresarias.

\section{Reflexiones finales}

En los últimos años, el panorama relativo a la participación de la mujer en el mercado laboral en América del Sur ha sufrido importantes cambios, que se traducen en una mayor participación femenina en las actividades económicas y productivas. Asimismo, se reconoce la importancia de fomentar la participación de la mujer en la economía mundial como agente de desarrollo, no solo en beneficio de su familia sino también de su comunidad.

El objetivo de este documento es examinar la situación actual y la evolución de la participación de las mujeres de América del Sur en actividades económicas y productivas. Se distinguen tres áreas de análisis: la mujer en el mercado laboral, es decir el tipo y la calidad del empleo al que las mujeres tienen acceso, la participación de la mujer en cargos de alta dirección, como gerencia o presencia en directorios, y las características de las mujeres empresarias y sus empresas.

El análisis de los distintos aspectos del empleo femenino, como participación, oferta y calidad, es necesario para el desarrollo de políticas públicas o programas de desarrollo eficaces en ese ámbito. Existe un consenso sobre la importancia de la generación de empleo, especialmente para los sectores más vulnerables, pues la inserción de las mujeres en situación de pobreza y pobreza extrema en el mercado laboral contribuiría a mejorar su estado de vulnerabilidad.

Los avances registrados en la inserción de la mujer en el mercado laboral incluyen el aumento de la participación femenina en la fuerza de trabajo, el incremento en la tasa de ocupación e incluso la disminución de la tasa de desempleo, al mismo tiempo que se observa una reducción de la brecha de género en dichos indicadores. Sin embargo, las mujeres siguen rezagadas en algunas áreas con respecto a la participación económica. A pesar de su disminución, la tasa de desempleo continúa siendo elevada. Las mujeres perciben en promedio una remuneración inferior a la de los hombres por el mismo trabajo realizado y se concentran en empleos de baja remuneración. Por último, la inserción en el mercado laboral no implica necesariamente un empleo pleno, pues las mujeres tienen mayores probabilidades de estar subempleadas, situación que limita su desarrollo económico y profesional.

Los esfuerzos deberían orientarse no solo a la generación y promoción del empleo, sino a mejorar su calidad y disminuir el empleo vulnerable, por ejemplo mediante la formalización de los 
trabajadores familiares y el establecimiento de protección social y legal para aquellas personas en situación de empleo vulnerable. Para reducir la segregación del empleo femenino a ocupaciones con un menor nivel de ingreso es necesario trabajar para la eliminación de los estereotipos y los papeles asignados en función del género. Esto es esencial para lograr la equidad en el mercado laboral, así como invertir en programas tempranos para despertar el interés de las mujeres en las ciencias y las matemáticas y fomentar su participación en sectores, como la minería o la industria, entre otras áreas tradicionalmente consideradas masculinas.

Otro aspecto en el que se observa una amplia brecha a favor de los hombres es en el ingreso medio. Si bien en los últimos años esta brecha se ha reducido, es necesario realizar mayores esfuerzos para eliminarla. Una de las causas probables de esta diferencia en el ingreso es la menor cantidad de horas que las mujeres dedican al empleo remunerado para, entre otras cosas, cumplir con las responsabilidades familiares y realizar las labores domésticas. Así, pese a que las mujeres tienen una menor participación en el trabajo remunerado con respecto a los hombres, su carga total de trabajo supera la de estos últimos, principalmente por su participación en actividades no remuneradas. Es necesario promover una mayor equidad en la distribución de las actividades no remuneradas para incrementar la participación de la mujer en aquellas remuneradas. La introducción de políticas de cuidado y la eliminación de los estereotipos de género que facilitan la división sexual del trabajo constituyen dos alternativas en ese sentido.

El acceso de las mujeres a los altos puestos directivos es muy limitado, mientras que su participación en los principales directorios es casi nula en América del Sur. Las propuestas para fomentar el acceso de la mujer a esos cargos incluyen combatir los prejuicios sobre las mujeres líderes, flexibilizar los horarios de trabajo, reducir la subjetividad de las evaluaciones de desempeño, abrir los procesos de selección, asegurar una cantidad de posiciones representativa para las mujeres en la alta dirección, mantener un equilibrio entre el número de hombres y mujeres en los equipos de trabajo y establecer políticas de recursos humanos que favorezcan la vida familiar, entre otras. Un aspecto importante que también debería tenerse en cuenta es brindar oportunidades para la reinserción en el mercado de trabajo a las mujeres que dejaron el mundo laboral, en tanto se encuentran en desventaja y necesitarían actualizar sus conocimientos.

En el documento se presentan las iniciativas de algunos países para promover el acceso de la mujer a los cargos de alta dirección, incluidos el establecimiento de cuotas y la implementación de políticas de equidad de género en las empresas privadas. Colombia fue el primer país de América del Sur que incluyó en su legislación un sistema de cuotas de género en los cargos con altos niveles de decisión de las organizaciones públicas. A partir de las experiencias en diversos países, se propone que el establecimiento de cuotas sea progresivo y vaya acompañado de la inserción de políticas de calidad de género en las empresas privadas.

Por último, se analiza el panorama de las mujeres empleadoras. Se observa que el número de mujeres dueñas de su propia empresa es menor en comparación con el de los hombres. A su vez, las mujeres se concentran en empresas pequeñas y su rentabilidad y desempeño medios son inferiores con respecto a las empresas dirigidas por hombres. Entre otros factores, esto se debe a la menor dedicación de las mujeres a sus empresas a causa de su mayor participación en actividades no remuneradas. Una vez más, se pone en evidencia la necesidad de promover una división equitativa de las labores domésticas y el cuidado familiar, para que las mujeres puedan incrementar su participación en actividades remuneradas.

La participación de la mujer en el mercado laboral tendría un efecto mayor en la erradicación de la pobreza y el empoderamiento económico de las mujeres si no persistieran las diferencias en la calidad del empleo, la brecha salarial, la división sexual del trabajo doméstico y las barreras en el acceso a altos cargos directivos. La legislación para aumentar la inserción de la mujer en el 
mercado laboral funcionó, a través del incremento del nivel educativo y un mayor control de la tasa de fecundidad. Ahora, es importante establecer políticas e iniciativas orientadas a la reducción de la brecha de género en materia de calidad del empleo y combatir los prejuicios y estereotipos que favorecen la asignación de determinados papeles a hombres y mujeres y limitan la participación plena de la mujer en las actividades económicas y productivas.

\section{Bibliografía}

Aguirre, R. y F. Ferrari (2014), "Las encuestas sobre uso del tiempo y trabajo no remunerado en América Latina y el Caribe: caminos recorridos y desafíos hacia el futuro", serie Asuntos de Género, № 122 (LC/L.3678/ Rev.1), Santiago, Comisión Económica para América Latina y el Caribe (CEPAL).

Alba, A. (2007), "Uso del tiempo, Ecuador 2007", presentación.

Avolio, B. (2008), "El perfil de las mujeres empresarias en el Perú", tesis, Lima, Pontificia Universidad Católica del Perú.

Banco Mundial (2012), World Development Report 2012: Gender Equality and Development, Washington, D.C. Batthyany, K. y L. Scuro (2010), "Uso del tiempo, cuidados y bienestar: desafíos de Uruguay y la región", Revista de Ciencias Sociales, vol. 23, № 27, Montevideo, Facultad de Ciencias Sociales, Universidad de la República.

CEPAL (Comisión Económica para América Latina y el Caribe) (2010), La hora de la igualdad: brechas por cerrar, caminos por abrir (LC/G.2432(SES.33/3)), Santiago.

_ (2004), Caminos hacia la equidad de género en América Latina y el Caribe (LC/L.2114(CRM.9-3)), Ciudad de México.

Daeren, L. (2000), "Mujeres empresarias en América Latina: El difícil equilibrio entre dos mundos de trabajo. Desafíos para el futuro", documento presentado en el Primer Seminario Internacional de la Mujer Empresaria "SIME 2000".

Dahlerup, D. (2006), Women, Quotas and Politics, Nueva York, Routledge.

Deloitte (2011), "Women in the Boardroom: A Global Perspective" [en línea] http://www.deloitte.com/assets/ Dcom-tanzania/Local\%20Assets/Documents/Deloitte\%20Article_Women\%20in\%20the\%20boardroom.pdf.

DGEC (Dirección General de Estadística y Censos) (2007a), "Encuesta anual de hogares 2005. Uso del tiempo", Informe de Resultados, № 328, Buenos Aires. (2007b), "Encuesta anual de hogares 2005. Uso del tiempo", Informe de Resultados, № 329, Buenos Aires.

División de Estadística de las Naciones Unidas/CEPAL (Comisión Económica para América Latina y el Caribe) (2011), "Comparación de datos nacionales e internacionales para el indicador 1.7 de los ODM, Proporción de la población ocupada que trabaja por cuenta propia o en una empresa familiar" [en línea] https://www. google.com/url?sa=t\&rct=j\&q=\&esrc=s\&source=web\&cd=4\&cad=rja\&uact=8\&ved=0ahUKEwiuqsirv_XL AhWCox4KHZ53CSYQFgggMAM\&url=http\%3A\%2F\%2Fmdgs.un.org\%2Funsd\%2Fmdg\%2FResource s\%2FAttach\%2FCapacity\%2Fcostarica\%2Fcostarica\%2FMDG\%2520ind\%25201-7\%2520data\%2520 summary\%2520sheet.doc\&usg=AFQjCNGPdjD3FLGyD25IWVtquVd4fVBXFA\&sig2=qSPrbDtU63UbBL 9z4hWr5A.

Eagly, A. y L. Carli (2007), "Women and the labyrinth of leadership”, Harvard Business Review [en línea] http:// harvardbusinessonline.hbsp.harvard.edu/b01/en/common/item_detail.jhtml?id=R0709C.

Foro Económico Mundial (2014), The Global Gender Gap Report 2014, Ginebra. (2013), The Global Gender Gap Report 2013, Ginebra.

Goldin, C. (2006), "The quiet revolution that transformed women's employment, education, and family", NBER Working Paper, № 11953, Cambridge, Massachusetts, National Bureau of Economic Research.

Governance Metrics International (2009), "Women on Boards: A Statistical Review by Country, Region, Sector and Market Index" [en línea] http://www.boardagender.org/stats-reports/global/243-governance-metricsinternational-women-on-boards-a-statistical-review-by-country-region-sector-and-market-index-2009.

Grant Thornton (2016), "Women in Business. Turning promise into Practice" [en línea] http://www.grantthornton. global/globalassets/wib_turning_promise_into_practice.pdf. (2015a), "Women in Business. The Path to Leadership" [en línea] http://www.grantthornton.global/en/ insights/articles/women-in-business-2015/.

(2015b), "En América Latina, las mujeres luchan por abrirse paso en el liderazgo empresarial" [en línea] http://www.grantthornton.com.pe/docs/notas-prensa/ibr-2015-women-in-business.pdf. 
(2013), Women in Senior Management: Setting the Stage for Growth [en línea] http://www.grantthornton. ie/db/Attachments/IBR2013_WiB_report_final.pdf.

Heller, L. (2010), "Mujeres emprendedoras en América Latina y el Caribe: realidades, obstáculos y desafíos", serie Mujer y Desarrollo, № 93 (LC/L.3116-P), Santiago, Comisión Económica de América Latina y el Caribe (CEPAL).

IBGE (Instituto Brasileño de Geografía y Estadística) (2012), "12 Fórum do Sistema Integrado de Pesquisas Domiciliares", Pesquisa piloto de uso do tempo 2009: primeiros resultados, Río de Janeiro. (2010), "Uso del tiempo y trabajo no remunerado", XII Encuentro Internacional de Estadísticas de Género.

INE (Instituto Nacional de Estadísticas) (2008), Encuesta exploratoria de uso del tiempo en el Gran Santiago. ¿Cómo distribuyen el tiempo hombres y mujeres?, Santiago.

INE (Instituto Nacional de Estadística) (2011), "Encuesta de empleo del tiempo 2009-2010: resultados definitivos", Notas de Prensa, Asunción, 14 de julio.

INE/FCS (Instituto Nacional de Estadísticas/Facultad de Ciencias Sociales) (2008), "Uso del tiempo y trabajo no remunerado en el Uruguay. Módulo de la Encuesta Continua de Hogares. Septiembre, 2007”, Montevideo.

INEC (Instituto Nacional de Estadística y Censos) (2012), "¿En qué utilizamos el tiempo los ecuatorianos? Periodo 2010-2012", Quito.

INSEE (Instituto Nacional de Estadística y Estudios Económicos) (2016), "Definitions, Methods, and Quality" [en línea] http://www.insee.fr/en/methodes/default.asp?page=definitions/population-active-bit.htm.

International IDEA/Universidad de Estocolmo/Unión Interparlamentaria (s/f), "Quota Database" [en línea] http://www.quotaproject.org/.

Joy, L. y otros (2007), "The Bottom Line: Corporate Performance and Women's Representation on Boards", Catalyst [en línea] http://www.catalyst.org/knowledge/bottom-line-corporate-performance-and-womensrepresentation-boards.

Kanter, R. (1977), Men and Women in Corporations, Nueva York, Basic Books.

Kelley, D. y otros (2015), Special Report. Women's Entrepreneurship, Global Entrepreneurship Monitor (GEM).

Klasen, S. y F. Lamanna (2009), "The impact of gender inequality in education and employment on economic growth: new evidence for a panel of countries", Feminist Economics, vol. 15, № 3.

Ley 581 (2000), "Ley 581 de 2000 (mayo 31)" [en línea] http://www.hsph.harvard.edu/population/womenrights/ colombia.women.00.pdf.

McKinsey \& Company (2007), Women Matter: Gender Diversity, a Corporate Perfomance Driver [en línea] http://www.raeng.org.uk/publications/other/women-matter-oct-2007.

Ministerio de la Mujer y Desarrollo Social (2011), Brechas de género en la distribución del tiempo, Lima.

Minniti, M., P. Arenius y N.S. Langowitz (2005), Global Entrepreneurship Monitor: 2004 Report on Women and Entrepreneurship [en línea] http://www.gemconsortium.org//download.asp?id=478.

MTPE (Ministerio de Trabajo y Promoción del Empleo) (2014), "Terminología" [en línea] http://www.mintra. gob.pe/mostrarContenido. php?id=165\&tip=909.

Naciones Unidas (1995), "Declaración y Plataforma de Acción de Beijing" [en línea] http://www.un.org/ womenwatch/daw/beijing/pdf/BDPfA\%20S.pdf.

Neider, L. (1987), "A preliminary investigation of female entrepreneurs in Florida", Journal of Small Business Management, vol. 25, №3.

Ñopo, H. (2012), New Century, Old Disparities. Gender and Ethnic Earnings Gaps in Latin America and the Caribbean, Nueva York, Banco Interamericano de Desarrollo.

OIT (Organización Internacional del Trabajo) (2016), Perspectivas sociales y del empleo en el mundo Tendencias 2016, Ginebra.

(2014a), World of Work Report 2014: Developing with Jobs, Ginebra.

_ (2014b), "Indicadores clave del mercado de trabajo" [en línea] http://www.ilo.org/empelm/what/ WCMS_114240/lang--en/index.htm.

_ (2014c), "Statistics and Databases. Definitions" [en línea] http://www.lo.org/ilostat/faces/help_home/ conceptsdefinitions?_adf.ctrl-state=agq4okx66_4\&clean=true\&_afrLoop=713400996779328. (2014d), Panorama laboral 2014. América Latina y el Caribe, Lima, Oficina Regional de la OIT para América Latina y el Caribe.

(2013a), Panorama laboral 2013. América Latina y el Caribe, Lima, Oficina Regional de la OIT para América Latina y el Caribe.

(2013b), Manual de uso e interpretación de las estadísticas laborales, Lima.

(2012), Global Employment Trends for Women, Ginebra. 
(2010), Women in Labour Markets: Measuring Progress and Identifying Challenges, Ginebra.

Orhan, M. y D. Scott (2001), "Why women enter into entrepreneurship: an explanatory model", Women in Management Review, vol. 15, N5, Emerald.

Otobe, N. (2011), "Global economic crisis, gender and employment: the impact and policy response", Employment Working Paper, N 74, Organización Internacional del Trabajo (OIT).

Pagés, C. y C. Piras (2010), El dividendo de género. Cómo capitalizar el trabajo de las mujeres, Nueva York, Banco Interamericano de Desarrollo.

Psacharopoulos, G. y Z. Tzannatos (1989), "Female labor force participation: an international perspective", The World Bank Research Observer, vol. 4, N², Washington, D.C., Banco Mundial.

Roland, S., D. Kelley y J. Kew (2012), 2012 Global Report [en línea] http://www.gemconsortium.org/docs/2645/ gem-2012-global-report.

Serida, J. y otros (2005), Global Entrepreneurship Monitor: Peru 2004-2005, Lima, Ediciones ESAN.

TUC Commission on Vulnerable Employment (2008), Hard Work, Hidden Lives [en línea] http://www. vulnerableworkers.org.uk/files/CoVE_full_report.pdf.

Verick, S. (2014), "Female labor force participation in developing countries" [en línea] http://wol.iza.org/articles/ female-labor-force-participation-in-developing-countries.pdf.

Villamizar, M.E. (2011), "Uso del tiempo de mujeres y hombres en Colombia. Midiendo la inequidad", serie Asuntos de Género, № 107 (LC/L.3298-P), Santiago, Comisión Económica para América Latina y el Caribe (CEPAL).

Weeks, J. y D. Seiler (2001), "Women's Entrepreneurship in Latin America: An Exploration of Current Knowledge", Washington, D.C., Banco Interamericano de Desarrollo [en línea] https://publications.iadb.org/bitstream/ handle/11319/5065/Women\%C2\%BFs\%20Entrepreneurship\%20in\%2OLatin\%20America\%3a\%20An\%20 Exploration\%20of\%20Current\%20Knowledge.pdf?sequence=1.

Wirth, L. (2012), "Las mujeres en la actividad empresarial y en puestos de dirección en América Latina”, Lima. 